\title{
Gene expression profiling of bovine endometrium during the oestrous cycle: detection of molecular pathways involved in functional changes
}

\author{
S Bauersachs ${ }^{1,2}$, S E Ulbrich ${ }^{3}$, K Gross $^{1}$, S E M Schmidt ${ }^{1}$, H H D Meyer ${ }^{3}$, R Einspanier ${ }^{4}$, \\ H Wenigerkind ${ }^{5}$, M Vermehren ${ }^{6}$, H Blum $^{2}$, F Sinowatz ${ }^{6}$ and E Wolf ${ }^{1,2}$ \\ ${ }^{1}$ Institute of Molecular Animal Breeding, Gene Center of the Ludwig-Maximilians University, Feodor-Lynen-Str. 25, 81377 Munich, Germany \\ ${ }^{2}$ Laboratory for Functional Genome Analysis (LAFUGA), Gene Centre of the Ludwig-Maximilians University, Munich, Germany \\ ${ }^{3}$ Physiology-Weihenstephan, Technical University of Munich, Freising, Germany \\ ${ }^{4}$ Institute of Veterinary Biochemistry, Free University of Berlin, Berlin, Germany \\ ${ }^{5}$ Bavarian Research Centre for Biology of Reproduction, Oberschleissheim, Germany \\ ${ }^{6}$ Institute of Veterinary Anatomy, Histology and Embryology, Ludwig-Maximilians University, Munich, Germany \\ (Requests for offprints should be addressed to E Wolf; Email: ewolf@Imb.uni-muenchen.de)
}

\begin{abstract}
The endometrium plays a central role among the reproductive tissues in the context of early embryo-maternal communication and pregnancy. It undergoes typical changes during the sexual/oestrous cycle, which are regulated by the ovarian hormones progesterone and oestrogen. To identify the underlying molecular mechanisms we have performed the first holistic screen of transcriptome changes in bovine intercaruncular endometrium at two stages of the cycle - end of day 0 (late oestrus, low progesterone) and day 12 (dioestrus, high progesterone). A combination of subtracted cDNA libraries and cDNA array hybridisation revealed 133 genes showing at least a 2-fold change of their mRNA abundance, 65 with higher levels at oestrus and 68 at dioestrus. Interestingly, genes were identified which showed differential expression between different uterine sections as well. The most prominent example was the UTMP (uterine milk protein) mRNA, which was markedly upregulated in the cranial part of the ipsilateral uterine horn at oestrus. A Gene Ontology classification of the genes with known function characterised the oestrus time by elevated expression of genes, for example related to cell adhesion, cell motility and extracellular matrix and the dioestrus time by higher expression of mRNAs encoding for a variety of enzymes and transport proteins, in particular ion channels. Searching in pathway databases and literature data-mining revealed physiological processes and signalling cascades, e.g. the transforming growth factor- $\beta$ signalling pathway and retinoic acid signalling, which are potentially involved in the regulation of changes of the endometrium during the oestrous cycle.
\end{abstract}

Journal of Molecular Endocrinology (2005) 34, 889-908

\section{Introduction}

During the sexual/oestrous cycle characteristic changes occur in the bovine endometrium regarding its composition and differentiation status. These changes are mainly regulated by the hormones progesterone $\left(\mathrm{P}_{4}\right)$, oestradiol and oxytocin (for review see Spencer et al. 2004). At oestrus, $\mathrm{P}_{4}$ levels are low and increase after ovulation until the highest levels at dioestrus. The increase of $\mathrm{P}_{4}$ is associated with the downregulation of its own receptor in the endometrial epithelium. Via oxytocin, luteolytic pulses of prostaglandin- $\mathrm{F}_{2 \alpha}$ are released leading to the regression of the ovarian corpus luteum, termed luteolysis (for review see Goff 2004). This results in the entry into a new ovarian cycle. In contrast, if an embryo is present and produces specific factors (e.g. interferon- $\tau$ ) the luteolytic mechanism in the endometrium is blocked and the functional corpus luteum is maintained, providing the basis for further development and the implantation of the conceptus. Although these basic means of hormonal regulations in the endometrium during the oestrous cycle are known, the detailed molecular mechanisms are not well understood.

In humans several studies using microarray analyses have been done investigating gene expression changes in the endometrium during the menstrual cycle. In two studies the proliferative phase was compared with the 'window of implantation' time (Kao et al. 2002, Borthwick et al. 2003) and in another two studies gene expression differences between the early secretory phase (2-4 days after the luteinising hormone (LH) surge) and the receptive phase (7-9 days after the LH surge) were investigated (Carson et al. 2002, Riesewijk et al. 2003). 
Two recent studies also provided first insights into changes of gene expression in the endometrium during the oestrous cycle comparing the proliferative vs secretory phase in the mouse (Tan et al. 2003) and the Rhesus monkey (Ace \& Okulicz 2004). For ruminants no comparable study has been done so far. Recently, we successfully applied a combination of subtracted cDNA libraries and cDNA array hybridisation to compare the mRNA expression profiles of bovine epithelial cells of the ipsilateral vs the contralateral oviduct (Bauersachs et al. 2003) and of cells from the ipsilateral oviduct at oestrus and dioestrus (Bauersachs et al. 2004) respectively. In the present study a similar approach was applied to analyse differential gene expression in the bovine intercaruncular endometrium at two important phases of the oestrous cycle - the time around ovulation (late oestrus) and the time of high $\mathrm{P}_{4}$ (dioestrus) when the endometrium is prepared for communication with an embryo. Based on the results of bioinformatic analyses and literature data-mining, molecular pathways involved in the regulation of specific functions of the bovine endometrium during the oestrous cycle were identified.

\section{Materials and methods}

\section{Synchronisation of oestrous cycle and collection of endometrial tissue samples}

Six cyclic heifers (Deutsches Fleckvieh) between 18 and 24 months old were cycle synchronised by injecting i.m. a single dose of $500 \mu \mathrm{g}$ cloprostenol (Estrumate; Essex Tierarznei, Munich, Germany) at dioestrus. Animals were observed for sexual behaviour (i.e. toleration, sweating, vaginal mucus) to determine standing heat, which occurred around $60 \mathrm{~h}$ after Estrumate injection. All animals were checked by ultrasound-guided follicle monitoring starting $48 \mathrm{~h}$ after Estrumate application at intervals of $6 \mathrm{~h}$. Blood samples were taken at day 20 and day 0 of the oestrous cycle every $6-9 \mathrm{~h}$ to determine serum LH levels (Schams \& Karg 1969) and just before slaughtering to determine serum $\mathrm{P}_{4}$ levels (Prakash et al. 1987). Three animals were slaughtered the morning after standing heat occurred within $8 \mathrm{~h}$ after the $\mathrm{LH}$ surge and three animals 12 days after oestrus; the former group displayed low serum $\mathrm{P}_{4}$ levels $(<1.0 \mathrm{ng} / \mathrm{ml})$ and the latter had high serum $\mathrm{P}_{4}$ levels $(>6.0 \mathrm{ng} / \mathrm{ml})$. The uterus was removed, opened longitudinally and divided into seven sections: corpus plus caudal, middle and cranial parts of the ipsilateral and the contralateral uterine horns (see Fig. la). Samples were carefully cut out from the lamina propria of the intercaruncular endometrium with a scalpel and immediately transferred into cryo-tubes and frozen in liquid nitrogen or on dry ice. Samples were stored at $-80{ }^{\circ} \mathrm{C}$ until further processing. Tissue samples for in situ hybridisation were also taken from the same animals. All experiments with animals were conducted with permission from the local veterinary authorities and in accordance with accepted standards of humane animal care.

\section{Generation of subtracted cDNA libraries and cDNA array hybridisation}

The production of subtracted libraries was done according to the suppression subtractive hybridisation (SSH) method (Diatchenko et al. 1996). Total RNA from endometrial tissue samples was isolated using Trizol reagent (Invitrogen) according to the manufacturer's instructions. Equal amounts of RNA of all seven sections of the uterus were pooled for the preparation of subtracted cDNA libraries for oestrus and dioestrus. The construction of the libraries was done as previously described (Bauersachs et al. 2003, 2004). For every library, $1536 \mathrm{cDNA}$ clones were randomly picked, the cDNA fragments amplified via PGR, spotted by a spotting robot onto small nylon membranes and analysed by array hybridisation (for details see Bauersachs et al. 2004). The cDNA arrays were hybridised with radioactively labelled probes derived from 42 tissue samples corresponding to the six animals. Up to 12 probes were hybridised in parallel. All hybridisations that were directly compared in the data analysis were processed simultaneously under equal conditions.

\section{Analysis of array data}

Array evaluation was done using AIDA Image Analyzer Software (Version 3.41; Raytest, Straubenhardt, Germany). Background was subtracted with the 'Weighted image regions' function. Raw data obtained by AIDA Array software were exported to Microsoft Excel and normalised to the mean signals of internal reference cDNAs of each array. Normalised data were compared pair-wise (oestrus vs dioestrus) using the datasets derived from the hybridisation experiments that were processed simultaneously. cDNA clones were set as differentially expressed between oestrus and dioestrus if they showed at least a 2-fold up- or downregulation in every oestrus-dioestrus pair in at least one section of the uterus. In Tables 1 and 2 the means of the ratios of the single uterine sections and the three pair-wise comparisons are shown. The ratios of the uterine sections were very similar for almost all genes. The coefficient of variation $(\mathrm{CV})$ values for the three comparisons are also shown. If a gene was represented on the array by more than one cDNA fragment the mean expression difference was calculated. Differential expression across the uterine segments (uterine horn cranial to corpus) was analysed by ANOVA (parametric test, Benjamini \& Hochberg false discovery rate) and a post-hoc test (Student-Newman-Keuls) using GeneSpring software 
Version 6.1 (Silicon Genetics, Redwood City, CA, USA). The analysis was done separately for the two sides of the uterus and the two times of the cycle. The four values of every cDNA derived from the cranial, middle and caudal uterine horn, and the corpus over the mean of all four values were used to consider the relative changes between these four uterine sections.

\section{Sequencing of cDNAs with differential hybridisation signals and data analysis}

cDNA fragments showing differential hybridisation signals were sequenced directly from spotting solutions by automated DNA sequencing (3100-Avant Genetic Analyzer; Applied Biosystems, Langen, Germany). Resulting sequences were compared with public sequence databases using the basic local alignment search tool at the National Center for Biotechnology Information (www.ncbi.nlm.nih.gov/blast/blast.cgi). cDNAs without similar entries in the 'nr' database were in addition compared with the 'est' database or the raw version of the bovine genome (http://pre.ensembl.org/ Multi/blastview? species $=$ Bos_taurus). Based on the human homologues simplified GOs were built using the GeneSpring software. Resulting data were supplemented with additional information from LocusLink (www.ncbi.nlm.nih.gov/locusLink/) and Entrez Gene (www.ncbi.nlm.nih.gov/entrez/query.fcgi? db = gene), and from the literature. Pathway analyses were done searching the KEGG (Kyoto Encyclopedia of Genes and Genomes) pathway database (www.genome.ad.jp/kegg/ pathway.html) and the literature (PubMed abstracts).

\section{Real-time RT-PCR}

The same 42 RNA samples as for array hybridisation were used. One microgram of each sample of total RNA was reverse transcribed in a total volume of $60 \mu \mathrm{l}$, containing $1 \times$ buffer (Promega), $0.5 \mathrm{mM}$ dNTPs (Roche), $2.5 \mu \mathrm{M}$ hexamer primers (Gibco BRL, Grand Island, NY, USA) and 200 U Superscript RT enzyme (Promega). Primers were designed to amplify specific fragments referring to selected regulated genes: CLDN10 (forward 5'-CATTTCATGCCAATCAGGG; reverse 5'-GGGTGGACGGTTACATCG (97 bp)), CPN1 (forward 5'-AGAGAGGCCCTGCGTGAC; reverse 5'AGAAAGAATGCTTCTTCTGGTG (90 bp)), EPHX2 (forward 5'-ACTCGTTGTGAACACCCGAG; reverse 5'-TAGAGGGCGGGTGAAACG (109 bp)), INHBA (forward 5'-CGATGGGGAGAACATCATC; reverse 5'-GTCTTCTTTGGACGGTCTCG (113 bp)), MGP (forward 5'-CGCGGAGACACGATGAAG; reverse 5'GAGGGAGAGGGGAGAATCG (161 bp), MS4A $8 B$ (forward 5'-CTGACGTGCTACGAAACGAAC; reverse 5'-GGCGAAACAAGGGAGGTATTC (191 bp)),
PENK (forward 5'-TCTGGAATGTGAGGGGAAAC; reverse 5'-GTTCTTAGCAAGCAGGTGGG (142 bp)), PTHLH (forward 5'-TCGCCTAACTCGAAGCGTGC; reverse 5'-TTTTGTTTTTCTTGCGGGG (148 bp)), SOX4 (forward 5'-ATTTCGAGTTCGCGGACTAC; reverse 5'-CGTTCAGTAGGTGAAGAGCAGG (101 bp)), UTMP (forward 5'-ATATCATCTTGTCGCGCATGG; reverse 5'-GTGCACATCGAACAGTTTGG (126 bp)), and the housekeeping gene Ubiquitin (forward 5'AGATCGAGGATAAGGAAGGGAT; reverse 5'GCTCGACGTCGAGGGTGAT (198 bp)) (referring to Neuvians et al. 2003). All amplified PCR fragments were sequenced with forward and reverse primers (3100-Avant Genetic Analyzer; Applied Biosystems) to verify the resulting PGR product. Thereafter the specific melting point of the amplified product served as verification of the product identity $\left(C L D N 10, C P N 1\right.$ and $M S 4 A 8 B 84^{\circ} \mathrm{C}$, EPHX2, PTHLH and MGP $85^{\circ} \mathrm{C}$, INHBA, PENK and UTMP $86{ }^{\circ} \mathrm{C}$, SOX4 $87^{\circ} \mathrm{C}$ and Ubiquitin $88^{\circ} \mathrm{C}$ ) (Pfaffl et al. 2003). For each of the following real-time PGR reactions, $1 \mu \mathrm{l}$ cDNA was used to amplify specific target genes. Quantitative real-time PCR reactions using the LightCycler DNA Master SYBR Green I protocol (Roche) were performed as described previously (Ulbrich et al. 2004). In each PGR reaction $17 \mathrm{ng} / \mu \mathrm{l} \mathrm{cDNA}$ were introduced and amplified in a $10 \mu \mathrm{l}$ reaction mixture (3 $\mathrm{mM} \mathrm{MgCl}_{2}, 0 \cdot 4 \mu \mathrm{M}$ primer forward and reverse each, $1 \times$ Light Cycler DNA Master SYBR Green I; Roche) using a real-time LightCycler instrument (Roche). The annealing temperature was $60^{\circ} \mathrm{C}$ for all reactions. To ensure an accurate quantification, a high temperature fluorescence measurement at $80{ }^{\circ} \mathrm{C}$ and $78{ }^{\circ} \mathrm{C}$ for EPHX2, INHBA, MGP, PENK, PTHLH and UTMP and CPN1, CLDN10, MS4A8B and Ubiquitin respectively, was undertaken in a fourth segment of the PCR. The cycle number required to achieve a definite SYBR Green fluorescence signal was calculated by the second derivative maximum method (crossing point, CP) (LightCycler software Version 3.5.28). The CP is correlated inversely with the logarithm of the initial template concentration. As negative controls, water instead of cDNA was used.

\section{Data analysis of real-time RT-PCR}

The CPs determined for the target genes were normalised against the housekeeping gene Ubiquitin. Results are presented as means $(n=3)$ (see Table 4). Expression ratios are presented as $\mathrm{x}$-fold regulation between oestrus and dioestrus relating to each section. Differences between day 0 and day 12 for each section were analysed using one-way ANOVA. The normal distribution was tested by the Kolmogorow-Smirnov method, followed by a Student's $t$-test to find significant differences (Sigma-Stat, Version 2.03). The level of significance ( $P$-value) is stated in Table 4. 


\section{In situ hybridisation}

Formalin-fixed $(3 \cdot 7 \%)$, paraffin-embedded samples were used to localise transcripts of PENK (proenkephalin), PTHLH (parathyroid hormone-like hormone), SAL1 (salivary lipocalin), INHBA (inhibin beta A) and UTMP (uterine milk protein precursor) within bovine uterus tissue (middle section of the ipsilateral horn). All samples except those used for detection of PENK mRNA were recovered during the oestrous phase. For PENK, material harvested at day 12 of the oestrous cycle was used. The same animals were used as for array hybridisation and real-time RT-PCR. Buffers $(50 \mathrm{mM}$ Tris-buffered saline (TBS) and $0 \cdot 1 \mathrm{M}$ sodium phosphate buffer) were adjusted to $\mathrm{pH} 7 \cdot 4$ unless otherwise noted. All solutions for in situ hybridisation were prepared using diethyl pyrocarbonate-treated water and glassware sterilised at $200{ }^{\circ} \mathrm{C}$. In addition, all steps prior to and during hybridisation were conducted under RNase-free conditions.

Sections were deparaffinised with xylene $(3 \times 10 \mathrm{~min})$, immersed in isopropanol $(2 \times 5 \mathrm{~min})$ and then allowed to air dry. Dried sections were submerged in $2 \times$ saline sodium citrate ( $\mathrm{SSC}, \mathrm{pH} \quad 7 \cdot 0$ ) and preheated in a Bain-Marie water bath $\left(80^{\circ} \mathrm{C}\right)$ for $10 \mathrm{~min}$ followed by gradual cooling off for $20 \mathrm{~min}$ at room temperature. Slides were then washed in distilled water $(2 \times 5 \mathrm{~min})$, TBS $(2 \times 5 \mathrm{~min})$ and permeabilised for $20 \mathrm{~min}$ with $0.05 \%$ proteinase E (VWR, Ismaning, Germany) in TBS at room temperature. Sections were relocated in TBS $(2 \times 5 \mathrm{~min})$ followed by distilled water $(2 \times 5 \mathrm{~min})$ and post-fixed for $10 \mathrm{~min}$ in $4 \%$ paraformaldehyde/PBS (pH 7•4). After washing in PBS $(2 \times 5 \mathrm{~min})$ and distilled water, slides were dehydrated in an ascending graded series of ethanol and air-dried. Hybridisation was carried out by overlaying the dried sections with $40 \mu \mathrm{l}$ of the corresponding biotinylated oligonucleotide probe $(100 \mathrm{pmol} / \mu \mathrm{l})$, diluted $1: 20$ in in situ hybridisation solution (DAKO, Munich, Germany) and incubating them in a humidified chamber (using cover slips to prevent drying-out) at $38{ }^{\circ} \mathrm{C}$ overnight. RNase-free hybridisation solution (DAKO) contained 60\% formamide, $5 \times \mathrm{SSC}$, hybridisation accelerator, RNase inhibitor and blocking reagents. Subsequently, slides were washed in $2 \times \mathrm{SSC}(2 \times 15 \mathrm{~min}$, preheated to $\left.38{ }^{\circ} \mathrm{C}\right)$, distilled water $(2 \times 5 \mathrm{~min})$ and TBS $(2 \times 5 \mathrm{~min})$. Detection of hybridised probes was performed using horseradish peroxidase-labelled $\mathrm{ABC}$ kit reagents developed with 3,3'-diaminobenzidine (DAKO) according to the manufacturer's instructions. Negative controls were done omitting the oligonucleotide probe and hybridisation with sense oligonucleotide probes. The sequences of the antisense oligonucleotides were as follows: INHBA: 5'-GATGATGTTGTGCGCATCG, UTMP: 5'-GTGCACATCCAACAGTTTGG, PTHLH:
5'-CAGGCTTGGAGTTAGGGGA，SAL1: 5'-GTAT CTGGTTCTCGGGCGT and PENK: 5'-GTTTCGC CTCAGATTCGAGA.

\section{Results}

To identify differentially expressed genes in the bovine endometrium between the (late) oestrous and the dioestrous stage a combination of subtracted cDNA libraries and cDNA array hybridisation was applied. Two subtracted cDNA libraries were produced for oestrus and dioestrus respectively, starting from a pool of RNA samples derived from seven sections of the uterus (Fig. 1a). One thousand five hundred and thirty-six randomly picked cDNA clones of each library were analysed by cDNA array hybridisation with 42 samples of six animals (oestrus $n=3$, dioestrus $n=3$ ).

First, array hybridisation data were analysed for differences between oestrus and dioestrus. This analysis revealed $444 \mathrm{cDNA}$ fragments showing at least 2-fold signal differences between oestrus and dioestrus in all three animal pairs (at least one uterine section). Figure $1 \mathrm{~b}$ shows the hybridisation signals of one cDNA fragment of the UTMP (uterine milk protein) gene derived from the probes of one animal at oestrus and one at dioestrus as an example. The sequence analysis of the cDNA fragments revealed 65 different genes or mRNAs with higher expression levels at oestrus (see Table 1). Sixty-two genes corresponded to genes of known or inferred function, either the bovine gene or the likely human orthologue. The most pronounced differences in mRNA levels were found for CLDN10 (claudin 10), INHBA (inhibin beta A), MMP2 (matrix metalloproteinase 2), PCSK5 (proprotein convertase 5), RARRES1 (retinoic acid (RA) receptor responder 1), SAL1 (salivary gland protein), TNC (tenascin C), UTMP and one unknown gene. The expression difference of these genes was termed 'on', i.e. no or very weak signals were detected at dioestrus by array hybridisation. The cDNA fragments of 25 genes were found more than once among the $444 \mathrm{cDNA}$ fragments, most frequently for SPARC (osteonectin, 31 cDNA fragments) and UTMP (29 cDNA fragments).

At dioestrus, 68 genes with increased expression were detected (Table 2). Fifty-six genes corresponded to genes of known or inferred function. The genes with the highest differences in mRNA levels were $A G T$ (angiotensinogen), ATP1B2 (Na/K ATPase), CYP26A1 (cytochrome P450 family member), DGAT2 (diacylglycerol O-acyltransferase), LY6 G6C and LY6 G6E (lymphocyte antigen complex), PENK (proenkephalin), TDGF1 (teratocarcinoma-derived growth factor 1) and a cDNA of unknown function. Again, for 25 genes more than one cDNA fragment was detected, most frequently for PENK (28 cDNA fragments) and GM2A 


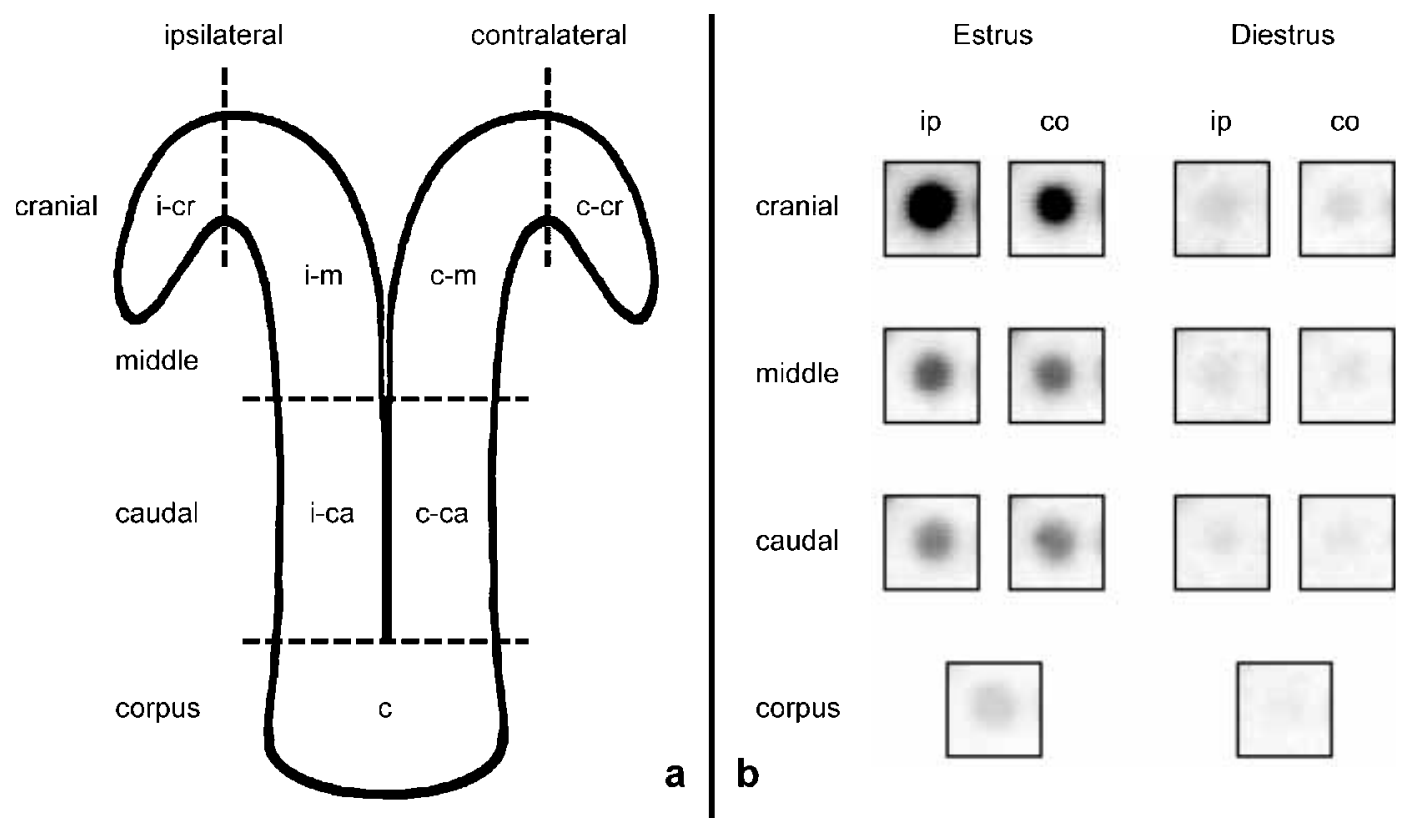

Figure 1 (a) Uterine sections. Endometrial tissue samples were collected from seven sections of the uterus: corpus (c) as well as caudal (ca), middle (m) and cranial (cr) parts of the ipsilateral and the contralateral uterine horns. (b) Array hybridisation. Radioactively labelled cDNA probes were prepared from the seven tissue samples of every animal (oestrus $n=3$, dioestrus $n=3$ ). These 42 probes were hybridised with randomly picked clones of two subtracted libraries, one for genes upregulated at oestrus and one for genes upregulated at dioestrus. Signals of one cDNA fragment of the UTMP gene derived from the probes of one animal at oestrus and one at dioestrus are shown.

(similar to GM2 ganglioside activator protein) (12 cDNA fragments).

In addition to the comparison of oestrus and dioestrus, the expression along the uterine horns from cranial to the corpus was investigated at the ipsilateral and the contralateral side at oestrus and dioestrus respectively. A few genes showed indeed expression differences from the cranial uterine horn to the corpus (see Table 3). Most of the genes with such expression differences showed a lower expression only in the corpus, e.g. the expression of the majority of genes was very similar across the uterine horns. The most pronounced expression gradient was observed for the UTMP mRNA during oestrus at both sides of the uterus. Gene expression was also analysed between the corresponding ipsilateral and contralateral sections of the uterine horns. Our recent study of the bovine oviduct (Bauersachs et al. 2003) and two studies of the bovine endometrium (Malayer et al. 1988, Williams et al. 1992) indicated that there could also be gene expression differences between the two uterine horns. For a few genes there was a tendency for an expression difference between the two uterine horns, but it was not significant.

For ten selected genes the expression in the endometrium was quantified by the use of real-time RT-PGR (Table 4). The same 42 RNA samples as for array hybridisation were used. All segments of the uterus were analysed for EPHX2 (epoxide hydrolase 2), MGP (matrix gla protein) and UTMP mRNA assuming a gradient along the uterine horns. For all other genes examined only the ipsi- and contralateral middle sections representing the total uterine horn were analysed. The mean crossing points (CP) normalised to the housekeeping gene Ubiquitin and the resulting expression ratios comparing oestrus and dioestrus are shown. The abundance of all investigated specific transcripts was remarkably different between the oestrus and dioestrus stage. The highest ratio between oestrus and dioestrus (150-fold) was found for the UTMP mRNA (cranial part of the ipsilateral uterine horn). The strong gradient of the UTMP mRNA abundance along the uterine horns at both sides of the uterus during oestrus was clearly confirmed, whereas for EPHX2 and $M G P$ only a tendency for a slightly higher expression in the cranial parts of the uterine horns was found. Overall the results of quantitative RT-PCR and array hybridisation correlated very well.

For five selected genes (INHBA, PTHLH, SAL1, UTMP and PENK) in situ hybridisation with bovine endometrial tissue sections were done to localise the mRNA expression in this complex tissue. A specific pattern of mRNA distribution was found for each of these genes (Fig. 2a and b). The hybridisation signal was always confined to cells of the endometrium and was 
Table 1 Mean fold-change of all uterine sections for the genes upregulated at oestrus

\section{Gene/cDNA/homologue description} 88128 MARC 1BOV B. taurus CDNA (UniGene Bt.5193, strongly similar to acid phosphatase 5, tartrate resistant $(H$. sapiens $))$

B. taurus mRNA for similar to alpha 2 actin

B. taurus $\beta$-actin

H. sapiens actin, gamma 2 , smooth muscle, enteric

B. taurus annexin A2

B. taurus apolipoprotein $\mathrm{E}$

B. taurus carbonic anhydrase II

H. sapiens claudin 10

B. taurus partial col1A1 gene for pro alpha 1(I) collagen

B. taurus collagen, type I, alpha 2

$H$. sapiens collagen, type $\mathrm{V}$, alpha 2

M. musculus procollagen, type $\mathrm{VI}$, alpha 3

B. taurus COL12 mRNA for type XII collagen

$H$. sapiens collagen, type $\mathrm{XV}$, alpha 1

$H$. sapiens cathepsin K (pycnodysostosis)

B. taurus decorin

B. taurus mRNA for similar to elongation

factor- $1-\gamma$

H. sapiens fibulin 1

M. musculus fibulin 5

B. taurus partial mRNA for fibronectin $(\mathrm{V}+\mathrm{l}-10)$ splice variant

$B$. taurus gap junction protein, $\alpha 1,43 \mathrm{kDa}$ (connexin 43)

H. sapiens IGFBP-6

B. taurus inhibin, beta $A$

B. taurus $\mathrm{mRNA}$ for similar to $40 \mathrm{~S}$ ribosomal protein SA (P40) (laminin receptor 1 )

B. taurus lectin, galactoside-binding, soluble, 1
$B$. taurus gastrin-releasing peptide

\section{Gene}

name

ACP5

ACTA2

ACTB

ACTG2

ANXA2

APOE

CA2

CLDN10

COL1A1

COL1A2

COL5A2

COL6A3

COL12A1

COL15A1

CTSK

DCN

EEF1G

FBLN1

FBLN5

FN1

GJA1

GRP

IGFBP6

INHBA

LAMR1

LGALS1

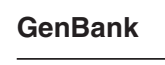

AW447045

AB098797

AY141970

NM 001615

NM_174716

NM_173991

AJ312112

NM_174520

NM 000393

BC057903

AB099882

NM_001855

NM 000396

NM_173906

AB098933

NM 001996

NM_011812

AJ320528

NM_174068

NM_178319

NM_002178

NM_174363

AB099011

NM_175782
NM 178572

NM_006984
Mean

$3 \cdot 1^{1}$

$2 \cdot 4$

$2 \cdot 1$

$3.0^{2}$

$2 \cdot 1^{2}$

$3 \cdot 3^{1}$

$4 \cdot 6^{2}$

$\mathrm{On}^{1}$

3.9

$4 \cdot 2^{2}$

$2 \cdot 8^{1}$

$5 \cdot 1^{2}$

$5.7^{1}$

3.7

$4 \cdot 2^{1}$

$1.9^{2}$

$2 \cdot 2^{2}$

3.9

$2 \cdot 6^{1}$

$3.5^{2}$

$3.5^{1}$

$2 \cdot 3$

$2 \cdot 0$

On 1

$1 \cdot 8^{2}$

$2 \cdot 8$
CV

(\%) Ontology

40

ECM remodelling

Cytoskeleton

Cell motility, cytoskeleton

Cell motility, cytoskeleton

ECM remodelling, cell growth

27 Transport, apoptosis-related function, cytoskeleton

ECM remodelling

Cell adhesion

ECM structural protein

ECM structural protein ECM structural protein

ECM, cell adhesion

ECM, cell adhesion

ECM structural protein

ECM remodelling

Signal transduction, ECM

remodelling

Protein biosynthesis

ECM, cell adhesion

ECM, cell adhesion

ECM, cell adhesion

Signal transduction, cell adhesion

Signal transduction, cell growth

Signal transduction, cell growth (-), proliferation (-)

Pregnancy, signal transduction, cell growth $(-)$, proliferation $(-)$, apoptosis-related function Signal transduction, cell adhesion

Immune-related, signal transduction, ECM remodelling, cell growth (-), proliferation (-), apoptosisrelated function, cell adhesion

$H$. sapiens melanoma antigen, family $D, 1$

$B$. taurus microfibril-associated glycoprotein-2 (MAGP2)

H. sapiens hypothetical protein MGC10540

B. taurus matrix metalloproteinase 2 (72 kDa type

IV collagenase)

H. sapiens mucin 16

H. sapiens Norrie disease (pseudoglioma)

B. taurus nephroblastoma overexpressed protein precursor gene

\begin{tabular}{|c|c|c|c|c|}
\hline MAGED1 & NM_006986 & $2 \cdot 4^{1}$ & 11 & Apoptosis-related function \\
\hline $\begin{array}{l}\text { MAGP2, } \\
\text { MFAP5 }\end{array}$ & NM_174386 & $3 \cdot 3$ & 42 & ECM structural protein \\
\hline MGC10540 & NM_032353 & $2 \cdot 5$ & 13 & 一 \\
\hline MMP2 & NM_174745 & $O n^{2}$ & & $\begin{array}{l}\text { ECM remodelling, } \\
\text { pregnancy, hydrolase }\end{array}$ \\
\hline MUC16 & AF361486 & $3 \cdot 8^{2}$ & 41 & Immune-related \\
\hline NDP & NM_000266 & $4 \cdot 8$ & 11 & $\begin{array}{l}\text { Signal transduction, cell } \\
\text { growth, Proliferation }\end{array}$ \\
\hline NOV & AF055076 & $7 \cdot 0$ & 27 & $\begin{array}{l}\text { Signal transduction, cell } \\
\text { motility, cell adhesion, cell } \\
\text { growth }\end{array}$ \\
\hline
\end{tabular}


Table 1 continued

H. sapiens nucleophosmin (nucleolar phosphoprotein B23, numatrin)

$B$. taurus procollagen-proline, 2-oxoglutarate

4-dioxygenase (proline 4-hydroxylase), beta polypeptide

H. sapiens procollagen C-endopeptidase enhancer

$H$. sapiens proprotein convertase subtilisin/kexin

type 5

$H$. sapiens pyruvate kinase, muscle

B. taurus peroxiredoxin 2

H. sapiens protease, serine, 11 (IGF binding)

H. sapiens patched homologue 2 (Drosophila)

B. taurus parathyroid hormone-like hormone

H. sapiens transcription factor RAM2

$H$. sapiens RA receptor responder (tazarotene induced) 1

$H$. sapiens regenerating islet-derived family, member 4

B. taurus mRNA for similar to ribosomal protein

L18a

$H$. sapiens ribosomal protein $\mathrm{L} 7 \mathrm{a}$

B. taurus mRNA for similar to $\mathrm{S} 100$ calcium-binding protein $\mathrm{A} 11$

CES014220 B. taurus skin cDNA library B. taurus cDNA (UniGene Bt.13796)

4059330 BARC 8BOV B. taurus cDNA (UniGene

Bt.21836)

$B$. taurus serine (or cysteine) proteinase inhibitor, clade A, member 1

$B$. taurus serine (or cysteine) proteinase inhibitor, clade $F$, member 1

$H$. sapiens serine (or cysteine) proteinase inhibitor, clade $\mathrm{H}$ (heat shock protein 47 ), member 1 , (collagen binding protein 1)

$H$. sapiens SRY (sex determining region Y)-box 4

$B$. taurus secreted protein, acidic, cysteine-rich (osteonectin)

H. sapiens Tax interaction protein 1

B. taurus thrombospondin

H. sapiens tenascin $\mathrm{C}$ (hexabrachion)

H. sapiens tubulin, alpha 1 (testis specific)

H. sapiens beta 5-tubulin (OK/SW-cl.56)

B. taurus uterine milk protein precursor

B. taurus vimentin

H. sapiens zinc finger protein 564 4062746 BARC 8BOV B. taurus (UniGene

Bt.13993)

Genomic scaffold 246248

\begin{tabular}{|c|c|c|c|c|}
\hline $\begin{array}{l}\text { Gene } \\
\text { name }\end{array}$ & GenBank & Mean & $\begin{array}{l}\text { CV } \\
(\%)\end{array}$ & Ontology \\
\hline NPM1 & NM_002520 & $1 \cdot 7^{2}$ & 22 & $\begin{array}{l}\text { Proliferation, } \\
\text { apoptosis-related function }\end{array}$ \\
\hline $\mathrm{P} 4 \mathrm{HB}$ & NM_174135 & $2 \cdot 7$ & 10 & ECM remodelling \\
\hline PCOLCE & NM_002593 & $2 \cdot 6$ & 18 & ECM remodelling \\
\hline PCSK5 & NM_006200 & $\mathrm{On}^{1}$ & - & $\begin{array}{l}\text { ECM remodelling, } \\
\text { hydrolase }\end{array}$ \\
\hline PKM2 & NM_002654 & 1.9 & 18 & Glycolysis \\
\hline PRDX2 & NM_174763 & $2 \cdot 1^{1}$ & 9 & Oxidoreductase \\
\hline PRSS11 & NM_002775 & $2 \cdot 6^{2}$ & 34 & $\begin{array}{l}\text { Signal transduction, cell } \\
\text { growth }(-) \text {, hydrolase }\end{array}$ \\
\hline PTCH2 & AY438664 & $2 \cdot 5^{2}$ & 43 & $\begin{array}{l}\text { Signal transduction, } \\
\text { proliferation }(-)\end{array}$ \\
\hline PTHLH & NM_174753 & $6 \cdot 3^{1}$ & 51 & $\begin{array}{l}\text { Signal transduction, } \\
\text { proliferation, pregnancy }\end{array}$ \\
\hline RAM2 & NM_018719 & $2 \cdot 7$ & 21 & Transcriptional regulation \\
\hline RARRES1 & NM_206963 & On & - & $\begin{array}{l}\text { Proliferation }(-) \text {, cell } \\
\text { adhesion }\end{array}$ \\
\hline REG4 & NM_032044 & $2 \cdot 2$ & 27 & Proliferation \\
\hline RPL18A & AB098916 & $2 \cdot 1^{2}$ & 15 & Protein biosynthesis \\
\hline RPL7A & NM_000972 & $2 \cdot 1^{2}$ & 19 & Protein biosynthesis \\
\hline S100A11 & AB099012 & $2 \cdot 7$ & 6 & Proliferation (-), cell motility \\
\hline SAL1 & CF769307 & On & - & $\begin{array}{l}\text { Signal transduction, } \\
\text { transport, pregnancy }\end{array}$ \\
\hline SEC61A1 & CK834803 & $2 \cdot 2^{2}$ & 8 & Transport \\
\hline SERPINA1 & NM_173882 & 3.0 & 14 & Immune-related \\
\hline SERPINF1 & NM_174140 & $2 \cdot 4$ & 11 & $\begin{array}{l}\text { Proliferation, } \\
\text { apoptosis-related function }\end{array}$ \\
\hline SERPINH1 & NM_001235 & $4 \cdot 3^{2}$ & 26 & ECM remodelling \\
\hline SOX4 & NM_003107 & $2 \cdot 6^{1}$ & 12 & Transcriptional regulation \\
\hline SPARC & NM_174464 & $3 \cdot 2$ & 3 & $\begin{array}{l}\text { ECM structural protein, } \\
\text { ECM remo-delling, cell } \\
\text { motility, proliferation (-) }\end{array}$ \\
\hline TAX1BP3 & NM_014604 & $2 \cdot 3^{1}$ & 13 & $\begin{array}{l}\text { Signal transduction, } \\
\text { proliferation }(-)\end{array}$ \\
\hline THBS1 & NM_174196 & $1 \cdot 7^{1}$ & 35 & $\begin{array}{l}\text { ECM, cell adhesion, cell } \\
\text { motility, signal transduction }\end{array}$ \\
\hline TNC & NM_002160 & $O n^{1}$ & & $\begin{array}{l}\text { Cell adhesion, ECM } \\
\text { structural protein, } \\
\text { immune-related }\end{array}$ \\
\hline TUBA1 & NM_006000 & $2 \cdot 1$ & 26 & Cytoskeleton \\
\hline TUBB & NM_-178014 & $2 \cdot 4^{1}$ & 26 & Cytoskeleton \\
\hline $\begin{array}{l}\text { UTMP, } \\
\text { LOC286871 }\end{array}$ & NM_174797 & $O n^{3}$ & & Immune-related, pregnancy \\
\hline VIM & NM_173969 & $2 \cdot 0^{2}$ & 29 & $\begin{array}{l}\text { Cytoskeleton, } \\
\text { immune-related }\end{array}$ \\
\hline ZNF564 & BC036481 & $2 \cdot 5^{2}$ & 40 & Transcriptional regulation \\
\hline- & CK837495 & $3 \cdot 0^{1}$ & 6 & - \\
\hline- & AAFC01272447 & On & & - \\
\hline
\end{tabular}

Gene name: official gene name/symbol from Entrez Gene; On: no expression detected at dioestrus; ${ }^{1}$ no expression detected in the corpus of one pair at dioestrus and oestrus; ${ }^{2}$ inconsistent expression in the corpus; ${ }^{3}$ no expression detected in the corpus of all animals; (-) negative regulation; (+) positive regulation 
Table 2 Mean fold-change of all uterine sections for the genes upregulated at dioestrus

\section{Gene/cDNA/homologue description}

$H$. sapiens ankyrin repeat and BTB (POZ) domain containing 1

Ovis ammon mRNA for angiotensinogen

20 alpha-hydroxysteroid dehydrogenase (cattle)

Alkaline phosphatase tissue non-specific

isoform/TNS-AP (cattle)

B. taurus Rho GDP dissociation inhibitor (GDI) beta

Human adult mRNA for Na/K ATPase beta 2 subunit 503071 MARC 2BOV B. taurus cDNA (UniGene Bt.24822, moderately similar to NP_059345-BAl1-associated protein 2, isoform 2) 721820 MARC 6BOV B. taurus cDNA (UniGene Bt.17278, strongly similar to NP_005495 branched chain aminotransferase 1 , cytosolic)

$H$. sapiens chromosome 5 open reading frame 18 H. sapiens cyclin B1

$H$. sapiens chloride channel $\mathrm{Ka}$

H. sapiens CCR4-NOT transcription complex, subunit 1

$H$. sapiens carboxypeptidase N, polypeptide 1,50 $\mathrm{kDa}$

H. sapiens cytochrome P450, family 26 , subfamily

A, polypeptide 1

B. taurus DGAT2 gene for diacylglycerol

O-acyltransferase 2

$H$. sapiens delta sleep inducing peptide,

immunoreactor

H. sapiens embryonic ectoderm development

H. sapiens ephrin-A1

$H$. sapiens epoxide hydrolase 2 , cytoplasmic

$H$. sapiens RNA-binding protein

603116 MARC 6BOV B. taurus cDNA (UniGene

Bt.17182, moderately similar to NP_005259.1 gap junction protein, beta 5)

Similar to $H$. sapiens GM2 ganglioside activator protein

$H$. sapiens helicase with zinc finger domain

Bubalus sp. mRNA for $\mathrm{NAD}^{+}$-dependent

15-hydroxyprostaglandin dehydrogenase

B. taurus isocitrate dehydrogenase $1(\mathrm{NADP}+)$, soluble

B.taurus mRNA for immunoglobulin light chain

H. sapiens integrin, beta 4

H. sapiens hypothetical protein $\mathrm{BC} 001573$

971446 BARC 5BOV B. taurus cDNA (UniGene

Bt.8371, moderately similar to low-density

lipoprotein receptor-related protein 2)

148109 MARC 4BOV B. taurus cDNA (UniGene

Bt.2346, moderately similar to NP_002337

lymphocyte antigen 6 complex, locus E)

$H$. sapiens lymphocyte antigen 6 complex, locus G6C

\begin{tabular}{|c|c|c|c|c|}
\hline $\begin{array}{l}\text { Gene } \\
\text { name }\end{array}$ & GenBank & Mean & $\begin{array}{l}\text { CV } \\
(\%)\end{array}$ & Ontology \\
\hline ABTB1 & NM_172027 & $2 \cdot 2$ & 26 & $\begin{array}{l}\text { Cell growth }(-) \text {, proliferation } \\
(-)\end{array}$ \\
\hline AGT & D17520 & On & - & Pregnancy \\
\hline AKR1B1 & S54973 & $6 \cdot 0$ & 15 & Dehydrogenase \\
\hline ALPL & S81600 & $4 \cdot 8$ & 10 & $\begin{array}{l}\text { ECM remodelling, } \\
\text { hydrolase }\end{array}$ \\
\hline ARHGDIB & NM_175797 & $5 \cdot 9$ & 9 & $\begin{array}{l}\text { Signal transduction, } \\
\text { immune-related, cell } \\
\text { adhesion }(-)\end{array}$ \\
\hline ATP1B2 & D87330 & On & - & Transport (ion channel) \\
\hline BAIAP2 & BM089351 & $3.1^{1}$ & 21 & Receptor activity \\
\hline BCAT1 & CB461808 & $5 \cdot 3$ & 11 & Proliferation $(+)$, transferase \\
\hline C5orf18 & NM_005669 & 3.6 & 3 & - \\
\hline CCNB1 & NM_031966 & 3.3 & 13 & Cell cycle related $(+)$ \\
\hline CLCNKA & NM_004070 & $5 \cdot 6$ & 35 & Transport (ion channel) \\
\hline CNOT1 & NM_016284 & $3 \cdot 0$ & 10 & - \\
\hline CPN1 & NM_001308 & $4 \cdot 7$ & 16 & Proteolysis, hydrolase \\
\hline CYP26A1 & NM_000783 & On & - & Pregnancy, transport \\
\hline DGAT2 & AJ534372 & On & - & Transferase \\
\hline DSIPI & NM_198057 & $5 \cdot 1$ & 12 & $\begin{array}{l}\text { Immune-related, } \\
\text { transcriptional regulation }\end{array}$ \\
\hline EED & NM_152991 & $2 \cdot 8$ & 31 & $\begin{array}{l}\text { Signal transduction, } \\
\text { transcriptional regulation, } \\
\text { pregnancy }\end{array}$ \\
\hline EFNA1 & NM_004428 & $3 \cdot 2$ & 43 & Signal transduction, kinase \\
\hline EPHX2 & NM_001979 & 7.5 & 32 & Immune-related, hydrolase \\
\hline FLJ20273 & NM_019027 & 2.9 & 12 & - \\
\hline GJB5 & CB427531 & $3 \cdot 1$ & 37 & Transport (channel) \\
\hline GM2A & NM_000405 & $9 \cdot 8$ & 43 & Glycolipid catabolism \\
\hline HELZ & NM_014877 & $3 \cdot 7$ & 31 & $\begin{array}{l}\text { Helicase activity, nucleic } \\
\text { acid binding }\end{array}$ \\
\hline HPGD & AJ222837 & $6 \cdot 7$ & 40 & $\begin{array}{l}\text { Pregnancy, oxidoreductase, } \\
\text { dehydrogenase }\end{array}$ \\
\hline IDH1 & NM_181012 & $4 \cdot 0$ & 36 & $\begin{array}{l}\text { Oxidoreductase, } \\
\text { dehydrogenase }\end{array}$ \\
\hline IG G1 & X62917 & $8 \cdot 1$ & 58 & Immune-related (antibody) \\
\hline ITGB4 & NM_000213 & $2 \cdot 8$ & 16 & $\begin{array}{l}\text { Cell adhesion, ECM } \\
\text { remodelling, signal } \\
\text { transduction, kinase }\end{array}$ \\
\hline LOC134147 & NM_138809 & $4 \cdot 2$ & 41 & Hydrolase \\
\hline LRP2 & CK8̈48654 & 8.0 & 18 & Transport \\
\hline LY6E & BE664006 & $3 \cdot 6$ & 18 & Immune-related \\
\hline LY6G6C & NM_025261 & On & - & Immune-related \\
\hline
\end{tabular}

Continued 
Table 2 Continued

4080472 BARC 9BOV B. taurus cDNA clone (UniGene Bt.9683, similar to lymphocyte antigen 6 complex, locus G6E)

H. sapiens cDNA FLJ37829 fis, weakly similar to $H$. sapiens mRNA for mucolipidin (UniGene Hs.535239 mucolipin 3)

H. sapiens hypothetical protein MGC15429

$H$. sapiens clone DNA176108 scavenger receptor hlg (UNQ2938)

$B$. taurus matrix Gla protein

H. sapiens membrane-spanning 4-domains, subfamily $\mathrm{A}$, member $8 \mathrm{~B}$

$H$. sapiens myotubularin related protein 3

M. musculus $\mathrm{N}$-myc downstream regulated 4 968490 MARC 4BOV B. taurus cDNA 3' (UniGene Hs.5025, H. sapiens nebulette)

4113753 BARC 9BOV B. taurus cDNA (UniGene

Bt.14398, moderately similar to

phosphatidylethanolamine-binding protein)

$H$. sapiens phosphatidylethanolamine-binding

protein 4

B. taurus proenkephalin

$H$. sapiens phospholipase $A 2$, group $X$

725142 MARC 6BOV B. taurus CDNA (UniGene

Bt.1286, moderately similar to NP_002880 retinoic acid receptor responder 2)

$H$. sapiens retinal short chain dehydrogenase reductase

4107201 BARC 9BOV B. taurus cDNA clone 9BOV33_L08 5' (UniGene Hs.445030 Rho-related

BTB domain containing 3 )

B. taurus RTN3 (reticulon 3)

H. sapiens secernin 1

$B$. taurus selenoprotein P-like protein precursor

$H$. sapiens serum/glucocorticoid regulated kinase

H. sapiens solute carrier family 16 (monocarboxylic acid transporters), member 11

H. sapiens SWI/SNF-related, matrix-associated, actin-dependent regulator of chromatin, subfamily $b$, member 1

H. sapiens SRY (sex determining region Y)-box 17

H. sapiens teratocarcinoma-derived growth factor 1

B. taurus transglutaminase 2

B. taurus tissue inhibitor of metalloproteinase 2

$H$. sapiens transducin-like enhancer of split 1

(E(sp1) homologue, Drosophila)

4070793 BARC 10BOV B. taurus cDNA (UniGene Bt.28503)

4081167 BARC 9BOV B. taurus cDNA (UniGene Bt.36133)

4082241 BARC 9BOV B. taurus cDNA (UniGene Bt.29337)

\begin{tabular}{|c|c|c|c|c|}
\hline $\begin{array}{l}\text { Gene } \\
\text { name }\end{array}$ & GenBank & Mean & $\begin{array}{l}\text { CV } \\
(\%)\end{array}$ & Ontology \\
\hline LY6G6E & CK965552 & $O n^{2}$ & - & $\begin{array}{l}\text { Immune-related, signal } \\
\text { transduction }\end{array}$ \\
\hline MCOLN3 & AK095148 & 4.8 & 48 & Transport \\
\hline MGC15429 & NM_032750 & $2 \cdot 4$ & 9 & Catalytic activity \\
\hline MGC45780 & AY358150 & $21 \cdot 1$ & 9 & Receptor activity \\
\hline MGP & NM_174707 & 4.5 & 19 & $\begin{array}{l}\text { ECM structural protein, } \\
\text { ECM remodelling }\end{array}$ \\
\hline MS4A8B & NM_031457 & $5 \cdot 3$ & 52 & Signal transduction \\
\hline MTMR3 & NM_153050 & $6 \cdot 4$ & 23 & Signal transduction \\
\hline NDRG4 & NM_145602 & 4.9 & 38 & Cell growth $(+)$, hydrolase \\
\hline NEBL & CK846036 & $6 \cdot 7$ & 13 & Actin-binding \\
\hline PBP & CK940308 & $3 \cdot 6$ & 26 & Signal transduction \\
\hline PEBP4 & NM_144962 & $3 \cdot 1$ & 32 & - \\
\hline PENK & NM_174141 & On & - & $\begin{array}{l}\text { Signal transduction, } \\
\text { pregnancy }\end{array}$ \\
\hline PLA2G10 & NM_003561 & $5 \cdot 2$ & 12 & Lipid catabolism, hydrolase \\
\hline RARRES2 & CB463961 & $2 \cdot 8$ & 26 & Cell growth, proliferation \\
\hline RDHE2 & NM_138969 & 4.9 & 40 & Dehydrogenase \\
\hline RHOВTВ3 & CK976167 & $2 \cdot 5$ & 30 & Signal transduction \\
\hline RTN3 & BK001797 & 3.9 & 34 & - \\
\hline SCRN1 & NM_014766 & 2.9 & 53 & Immune-related \\
\hline SEPP1 & NM_174459 & $2 \cdot 9$ & 32 & Transport \\
\hline SGK & NM_005627 & $2 \cdot 1$ & 20 & $\begin{array}{l}\text { Signal transduction, kinase, } \\
\text { transferase, apoptosis, } \\
\text { transport }\end{array}$ \\
\hline SLC16A11 & NM_153357 & $7 \cdot 6$ & 21 & Transport \\
\hline SMARCB1 & NM_003073 & $7 \cdot 8$ & 48 & $\begin{array}{l}\text { Cell cycle related, } \\
\text { transcriptional regulation }\end{array}$ \\
\hline SOX17 & NM_022454 & $3 \cdot 0$ & 25 & $\begin{array}{l}\text { Transcription regulation, } \\
\text { pregnancy }\end{array}$ \\
\hline TDGF1 & NM_003212 & On & & $\begin{array}{l}\text { Signal transduction, cell } \\
\text { growth }(+)\end{array}$ \\
\hline TGM2 & NM_177507 & 4.4 & 10 & $\begin{array}{l}\text { Apoptosis related, } \\
\text { transferase }\end{array}$ \\
\hline TIMP2 & NM_174472 & $5 \cdot 5$ & 12 & $\begin{array}{l}\text { ECM remodelling, } \\
\text { pregnancy }\end{array}$ \\
\hline TLE1 & NM_005077 & $3 \cdot 2$ & 13 & $\begin{array}{l}\text { Signal transduction, } \\
\text { transcriptional regulation }\end{array}$ \\
\hline- & CK946314 & 4.9 & 28 & - \\
\hline - & CK965794 & $2 \cdot 7$ & 16 & - \\
\hline - & CK966960 & $4 \cdot 8$ & 34 & - \\
\hline
\end{tabular}

Continued 
Table 2 Continued

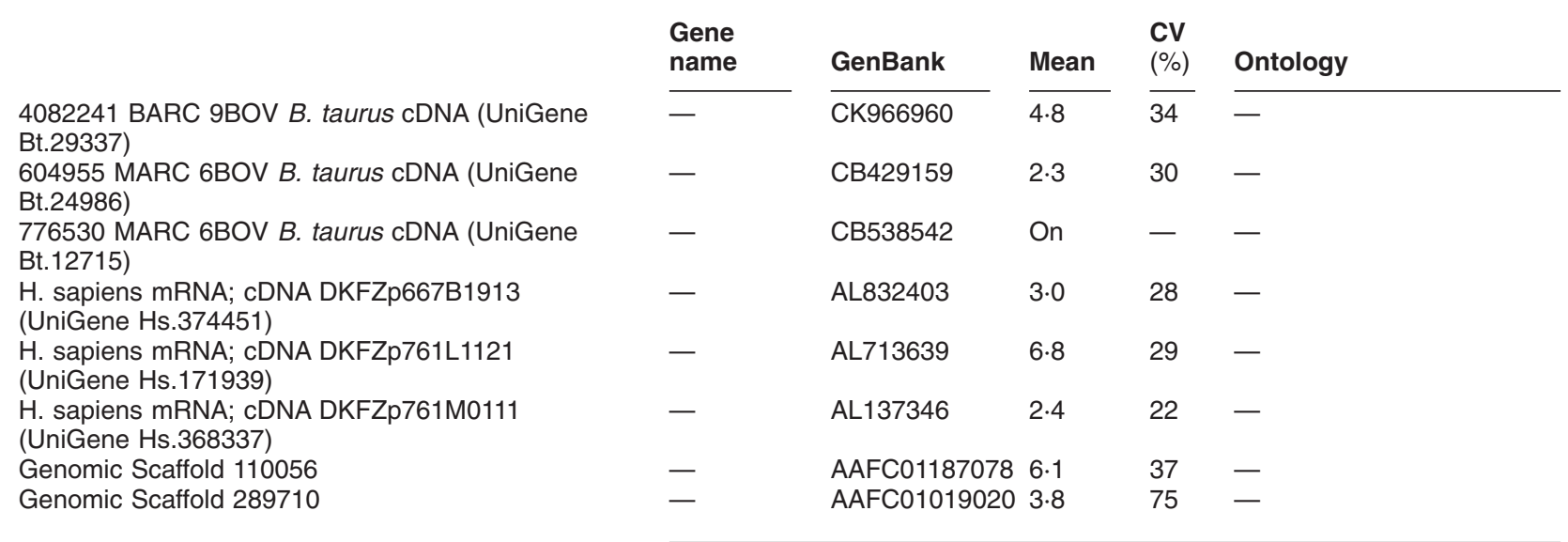

Gene name: official gene name/symbol from Entrez Gene; On: no expression detected at oestrus; ${ }^{1}$ inconsistent expression in the corpus; ${ }^{2}$ no expression detected in all uterine sections of one animal pair at dioestrus and oestrus; (-) negative regulation; (+) positive regulation

absent in the myometrium and the serosa. No specific signal was observed in sections hybridised with the sense strand (Fig. 2c) or in sections incubated with buffer only instead of the oligonucleotide probes. Considerable levels of the INHBA message were detected in the supranuclear area of the surface epithelium. The

Table 3 Gradients of gene expression from the cranial uterine horn to the corpus

\section{Gene/cDNA description}

88128 MARC 1BOV B. taurus cDNA

(UniGene Bt.5193, strongly similar to acid

phosphatase 5 , tartrate resistant

(H. sapiens))

Ovis ammon mRNA for angiotensinogen

$H$. sapiens epoxide hydrolase 2 ,

cytoplasmic

Similar to $H$. sapiens GM2 ganglioside activator protein

B. taurus IGFBP-4

H. sapiens integrin, beta 4

$M$. musculus $\mathrm{N}$-myc downstream regulated 4

H. sapiens phosphorylase kinase, gamma 2

$B$. taurus uterine milk protein precursor

\begin{tabular}{|c|c|c|c|c|c|c|c|}
\hline $\begin{array}{l}\text { Gene } \\
\text { name }\end{array}$ & GenBank & Gradient & cran & mid & caud & corp & Pattern \\
\hline \multirow[t]{2}{*}{ ACP5 } & AW447045 & Es ip & $4 \cdot 3$ & 1.9 & 1.5 & 1.0 & 2111 \\
\hline & & Es co & $4 \cdot 1$ & $2 \cdot 7$ & 1.5 & 1.0 & 3211 \\
\hline AGT & D17520 & Di co & $3 \cdot 1$ & 1.7 & $1 \cdot 8$ & $1 \cdot 0$ & 2111 \\
\hline \multirow[t]{4}{*}{ EPHX2 } & NM_001979 & Di ip & $2 \cdot 3$ & $1 \cdot 8$ & $2 \cdot 0$ & 1.0 & 2221 \\
\hline & qPCR & Di ip & 1.6 & $1 \cdot 1$ & 1.4 & 1.0 & - \\
\hline & & Di co & $2 \cdot 7$ & $2 \cdot 0$ & 1.6 & 1.0 & 3221 \\
\hline & qPCR & Di co & 1.6 & $1 \cdot 2$ & $1 \cdot 3$ & 1.0 & - \\
\hline \multirow[t]{2}{*}{ GM2A } & NM_000405 & Di ip & $3 \cdot 2$ & 2.5 & $2 \cdot 8$ & 1.0 & 2221 \\
\hline & & Di co & $3 \cdot 2$ & $2 \cdot 7$ & $2 \cdot 2$ & 1.0 & 2221 \\
\hline \multirow[t]{2}{*}{ IGFBP4 } & NM_174557 & Es ip & 3.9 & $2 \cdot 2$ & $2 \cdot 2$ & 1.0 & 3221 \\
\hline & & Es co & $2 \cdot 8$ & 1.9 & 1.9 & 1.0 & 2221 \\
\hline ITGB4 & NM_000213 & Di co & 2.5 & 1.8 & 1.6 & 1.0 & 3221 \\
\hline \multirow[t]{2}{*}{ NDRG4 } & NM_145602 & Di ip & $2 \cdot 8$ & $2 \cdot 6$ & $2 \cdot 7$ & 1.0 & 2221 \\
\hline & & Di co & 3.9 & 3.4 & $2 \cdot 8$ & 1.0 & 2221 \\
\hline PHKG2 & NM_000294 & Di ip & $3 \cdot 2$ & 3.0 & 3.4 & $1 \cdot 0$ & 2221 \\
\hline \multirow[t]{4}{*}{ UTMP } & NM_174797 & Es ip & $30 \cdot 6$ & $6 \cdot 7$ & $3 \cdot 2$ & 1.0 & 2111 \\
\hline & $\mathrm{qPC}$ & Es ip & $34 \cdot 5$ & $9 \cdot 1$ & $2 \cdot 3$ & 1.0 & - \\
\hline & & Es co & $20 \cdot 5$ & $6 \cdot 6$ & 3.7 & 1.0 & 4321 \\
\hline & qPCR & Es co & $20 \cdot 5$ & 11.4 & $5 \cdot 3$ & 1.0 & - \\
\hline - & CK960198 & Di ip & $3 \cdot 1$ & $2 \cdot 8$ & 3.0 & 1.0 & 2221 \\
\hline \multirow[t]{3}{*}{-} & Z48207 & Es ip & $2 \cdot 7$ & $2 \cdot 2$ & $2 \cdot 2$ & 1.0 & 2221 \\
\hline & & Es co & 2.5 & 2.5 & 2.4 & 1.0 & 2221 \\
\hline & & Di co & $3 \cdot 1$ & 1.9 & 1.3 & 1.0 & 2111 \\
\hline
\end{tabular}

Gradient: Es ip: oestrus, ipsilateral; Es co: oestrus contralateral; Di ip: dioestrus, ipsilateral; Di co: dioestrus contralateral; Pattern: pattern represents significance of signal differences revealed by the post-hoc test 

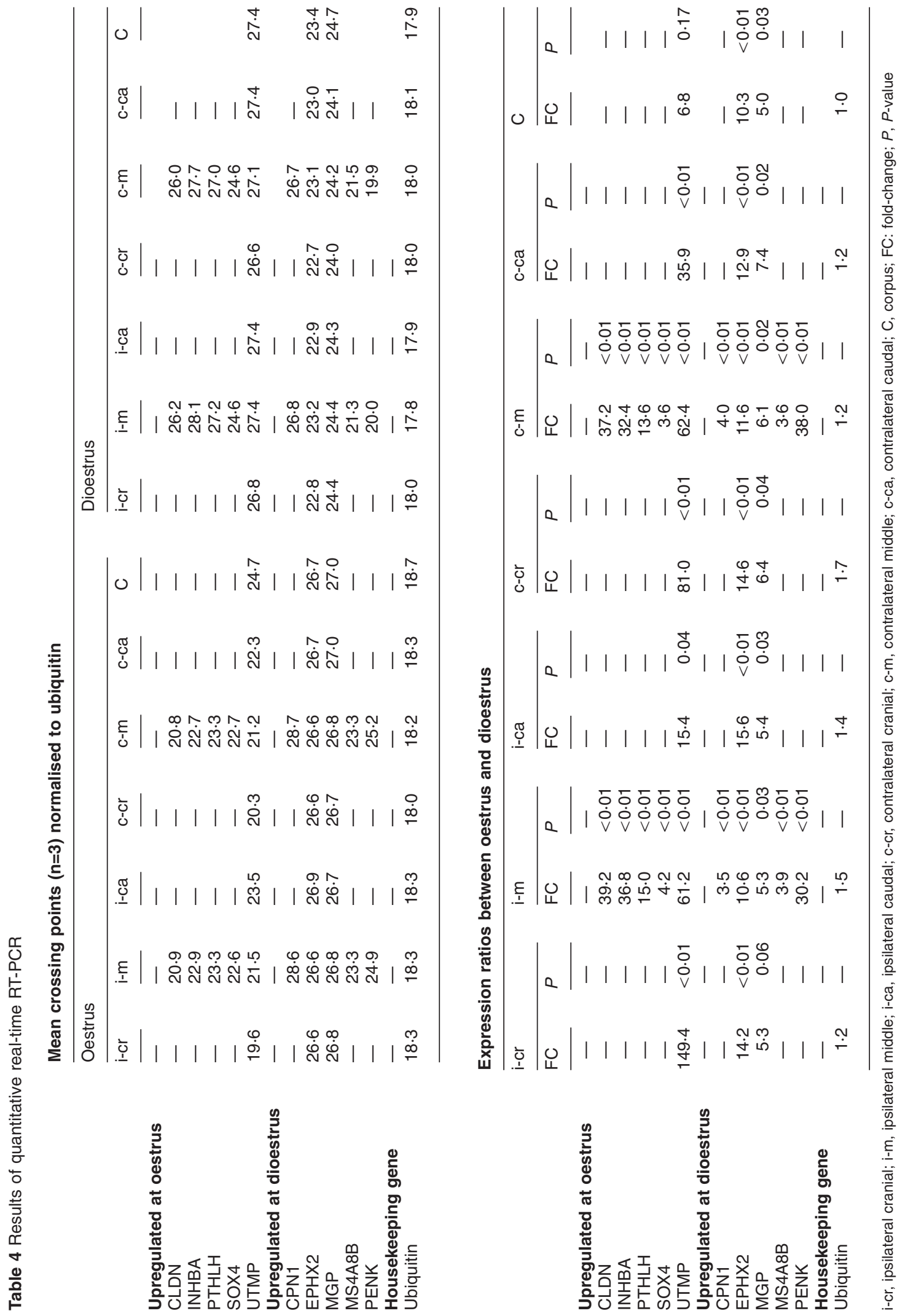


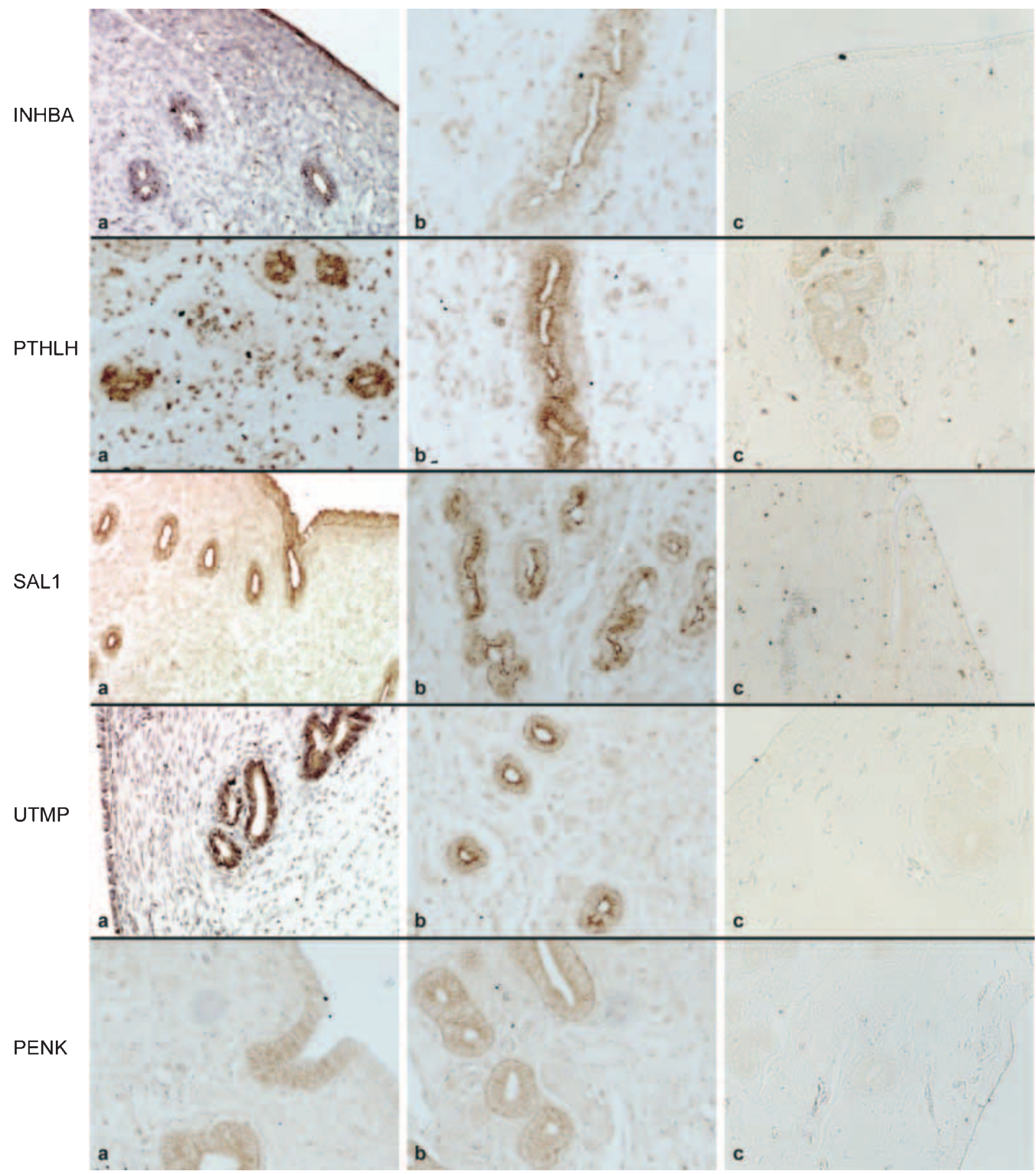

Figure 2 In situ hybridisation. Tissue samples of the middle part of the ipsilateral uterine horn were used from animals slaughtered at oestrus for the detection of INHBA, PTHLH, SAL1 and UTMP mRNAs or at dioestrus for PENK mRNA. Endometrial sections near the epithelial surface (a), of the deep uterine glands (b), and hybridised with the corresponding sense oligonucleotide (c) are shown.

superficial uterine glands also showed a distinct staining of several cells within a cross-section of the gland. In the deep uterine glands adjacent to the myometrium, the INHBA message appeared somewhat reduced, but was 
still more pronounced in the apical area of the glandular epithelium. Most of the fibroblasts in the endometrium displayed a weak hybridisation signal. High levels of PTHLH mRNA were found in the uterine surface epithelium and in the deep uterine glands. Also the fibroblasts of the endometrium showed a distinct staining. In the superficial uterine glands, the hybridisation signal was less pronounced and appeared concentrated to the supranuclear area of the glands. Strong staining for SAL1 mRNA could be demonstrated in the uterine surface epithelium and in the supranuclear epithelial area of the superficial uterine glands. Deep uterine glands stained generally more weakly, with a distinct signal in the apical region of the glands. mRNA for UTMP was detected in dispersed epithelial cells of the surface epithelium but distinct staining was found in the epithelium of the superficial and deep uterine glands. PENK was weakly expressed in the surface epithelium but the signal intensity increased in the uterine glands.

To deduce a picture of the regulatory processes that proceed during the oestrous cycle in the endometrium from the changes at the mRNA level, two bioinformatic approaches were applied. At first, a functional classification of the identified genes was done by building a simplified Gene Ontology (GO) for genes upregulated either at oestrus (see Table 1, Ontology) or at dioestrus (see Table 2, Ontology). For a graphical illustration the numbers of genes assigned to the 19 functional groups at oestrus and dioestrus are compared in Fig. 3. Some biological processes or molecular functions clearly dominated either at oestrus or at dioestrus. At oestrus the functional groups 'Cytoskeleton', 'Cell motility', 'Cell adhesion', 'Extracellular matrix (ECM) structural proteins', 'ECM remodelling' and 'Proliferation' clearly prevail. At dioestrus, genes of several groups of enzymes and 'Transport' are more upregulated.

Furthermore, involved pathways and signalling cascades were identified by the analysis of KEGG pathways and a literature search. Thirteen pathways and the assigned genes at oestrus and dioestrus are listed in Table 5. The highest number of genes (17 genes) was assigned to the transforming growth factor- $\beta$ (TGF- $\beta$ ) signalling pathway. Most of these genes (14 genes) were upregulated at oestrus and corresponded to target genes or to inhibitors of this pathway. In Fig. 4 a simplified TGF- $\beta$ signalling pathway based on the Homo sapiens reference pathway derived from the KEGG pathway database with the assigned genes is shown. For the Prostaglandin metabolism (four genes) as well as for the Phosphoinositide signalling (four genes) only such genes could be assigned that were upregulated at dioestrus. In contrast, for the Phospholipase C pathway (three genes) and also for the Ribosome pathway (four genes) only such genes were found that were upregulated at oestrus.

Finally, a comparison of the genes found in this and other studies of the human, the non-human primate

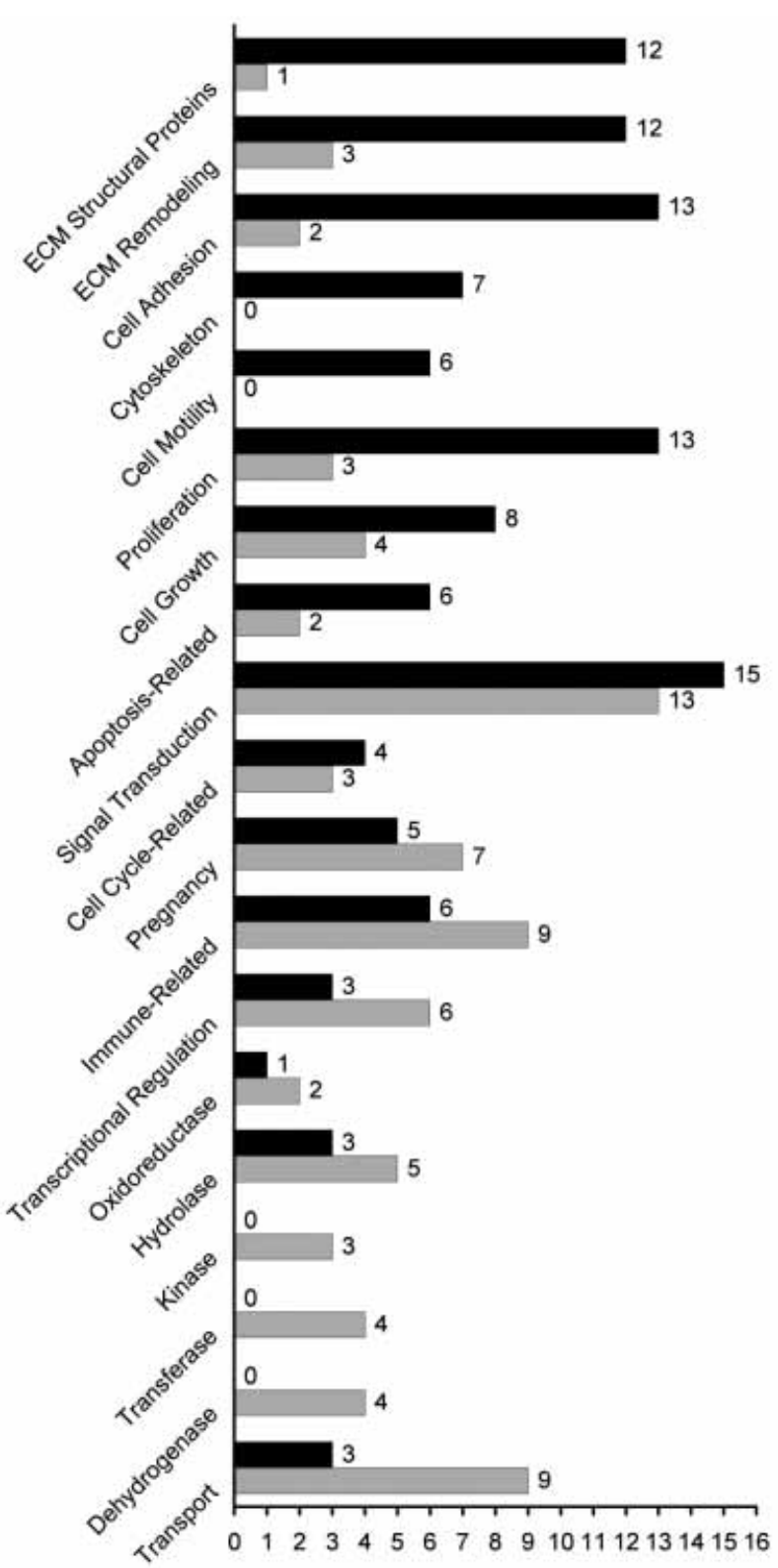

Figure 3 Comparison of the simplified GO at oestrus and dioestrus. For the differentially expressed genes of known or inferred function a simplified GO was built. The number of genes is shown for every GO group at oestrus (black bars) and at dioestrus (grey bars) respectively.

(Rhesus monkey), and the mouse system (Carson et al. 2002, Kao et al. 2002, Borthwick et al. 2003, Riesewijk et al. 2003, Tan et al. 2003, Ace \& Okulicz 2004) was done (Table 6). The cycle stages that were compared in these studies are stated in the footnotes of Table 6 . The overall overlap with these studies was 34 genes. Considering closely related genes of the same gene family the overlap was even higher (data not shown). 
Table 5 Assignment to cellular pathways

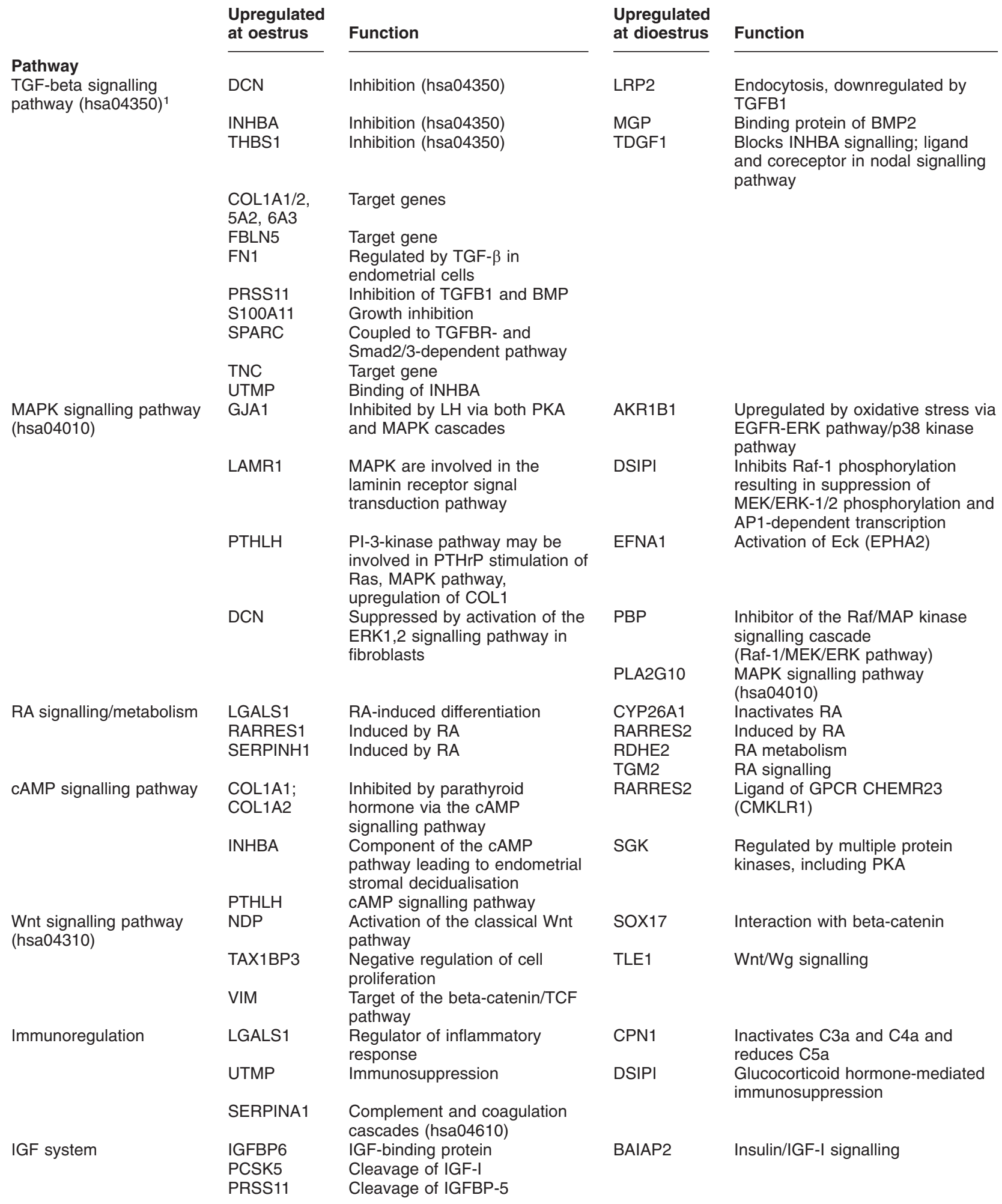


Table 5 Continued

\begin{tabular}{|c|c|c|c|c|}
\hline & $\begin{array}{l}\text { Upregulated } \\
\text { at oestrus }\end{array}$ & Function & $\begin{array}{l}\text { Upregulated } \\
\text { at dioestrus }\end{array}$ & Function \\
\hline \multirow{3}{*}{$\begin{array}{l}\text { Prostaglandin and } \\
\text { leukotriene metabolism } \\
\text { (hsa00590) }\end{array}$} & & & AKR1B1 & $\begin{array}{l}\text { Glycerolipid metabolism } \\
\text { (hsa00561) }\end{array}$ \\
\hline & & PLA2G10 & hsa00590 & \\
\hline & & $\mathrm{EPHX} 2$ & $\begin{array}{l}\text { Prostaglandin } \\
\text { metabolism }\end{array}$ & \\
\hline \multirow{3}{*}{ Ribosome (hsa03010) } & RPL18A & hsa03010 & & \\
\hline & LAMR1 & hsa03010 & & \\
\hline & NPM1 & Ribosome biogenesis pathway & & \\
\hline EGFR pathway & TNC & $\begin{array}{l}\text { Negative regulation of } \\
\text { Rho-ROCK pathway via EGFR } \\
\text { pathway }\end{array}$ & TIMP2 & $\begin{array}{l}\text { Suppresses EGF-mediated } \\
\text { mitogenic signalling }\end{array}$ \\
\hline $\begin{array}{l}\text { Sonic hedgehog } \\
\text { signalling }\end{array}$ & PTHLH & Hedgehog signalling pathway & & \\
\hline \multirow[t]{3}{*}{$\begin{array}{l}\text { Phospholipase C } \\
\text { pathway }\end{array}$} & GRP & $\begin{array}{l}\text { Stimulation of the GRP receptor } \\
\text { activates phospholipase C } \\
\text { pathway }\end{array}$ & & \\
\hline & MMP2 & $\begin{array}{l}\text { Generation is mediated by } \\
\text { activation of phospholipase } A(2)\end{array}$ & & \\
\hline & PTHLH & $\begin{array}{l}\text { Gq-mediated phospholipase } \\
\mathrm{C} / \mathrm{Ca} 2^{+} \text {signalling, apoptosis }\end{array}$ & & \\
\hline \multirow{4}{*}{$\begin{array}{l}\text { Phosphoinositide } \\
\text { signalling pathway }\end{array}$} & & & SGK & Component of PI-3-kinase \\
\hline & & & & signalling pathway \\
\hline & & & EFNA1 & Increased PI-3-kinase activity \\
\hline & & & MTMR3 & Phosphoinositide signalling \\
\hline
\end{tabular}

${ }^{1}$ ID of the $H$. sapiens reference pathway

Thirteen genes showed a similar regulation, the regulation of 17 genes was contrary, and four genes were mentioned as 'expressed' in the study of Borthwick et al. (2003).

\section{Discussion}

The aim of this study was the identification of differentially expressed genes in the bovine endometrium during the oestrous cycle, in particular between the late oestrus and the dioestrus stage to uncover regulatory pathways involved in the control of the complex cycle-dependent changes in this tissue. Therefore, a combination of SSH and cDNA microarrays was used. This resulted in a relatively large number of genes differentially expressed between oestrus and dioestrus (133 genes) and also a couple of genes with clear expression differences between the uterine sections. The number of differentially expressed genes between the oestrus and the dioestrus stage was comparable with that found in similar studies in the mouse, the Rhesus monkey and in humans, which have been done with high-density cDNA or oligonucleotide arrays respectively (Borthwick et al. 2003, Tan et al. 2003, Ace \& Okulicz 2004).

Using quantitative real-time RT-PCR the results of the array hybridisation were clearly confirmed. The correlation of the data was very good, although microarray data usually do not provide exact quantitative expression differences as quantitative PCR. Reasons for minor deviations in expression ratios have already been discussed elsewhere (Bauersachs et al. 2004). The analysis of genes with high expression ratios between oestrus and dioestrus could be done very precisely by real-time RT-PCR, extending the qualitative array result 'on' referring to no signal at one cycle phase because of too low expression signals. For instance, the expression of UTMP mRNA in the ipsilateral cranial endometrium at oestrus was almost 150-fold higher than at dioestrus.

The classification of the identified genes based on GOs revealed that upregulation of mRNAs of distinct functional groups clearly dominated at oestrus or dioestrus. At oestrus the striking upregulation of mRNAs for proteins of the ECM and for proteins involved in 


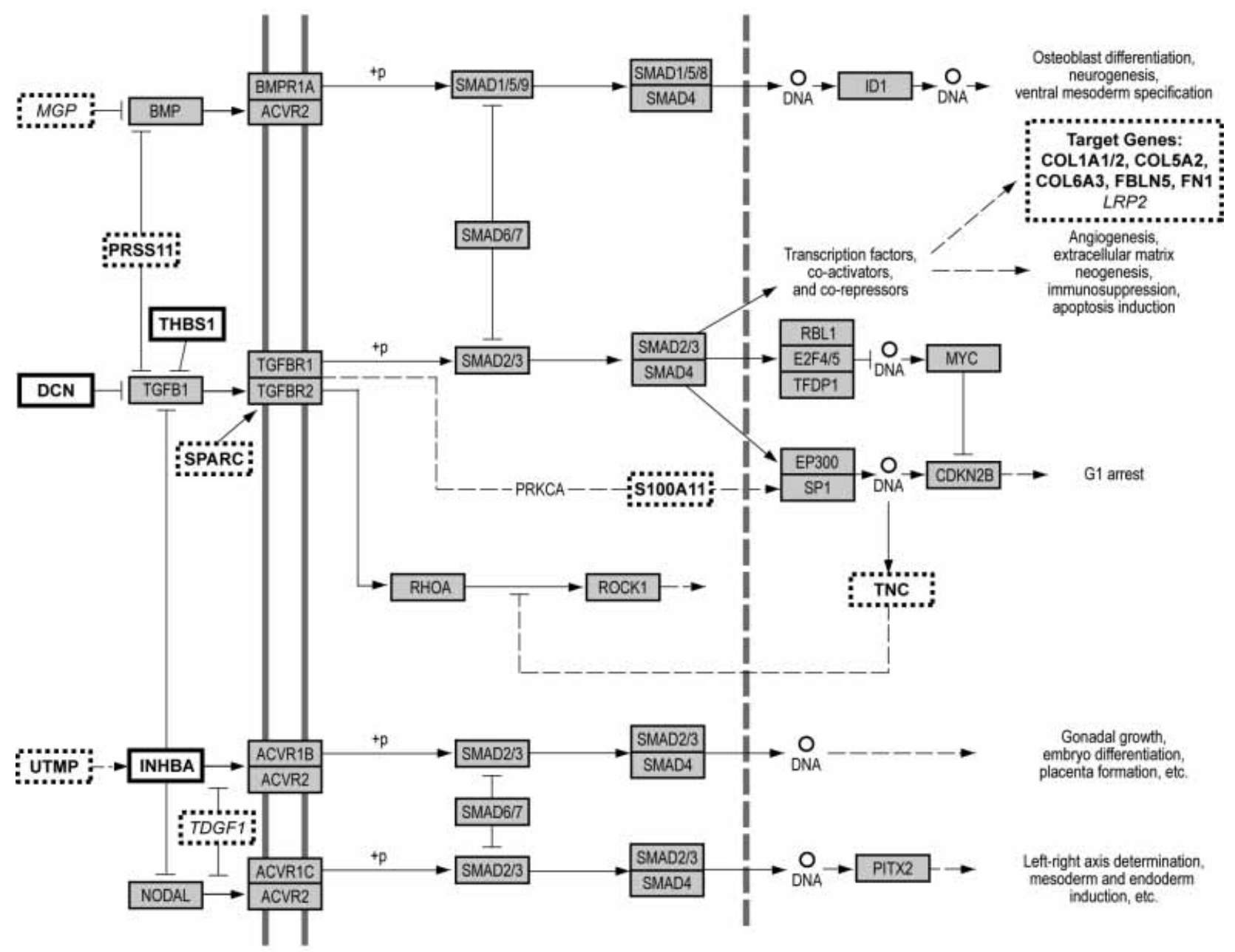

Extracellular space

Cytoplasm

Nucleus

Figure 4 Genes involved in the TGF- $\beta$ signalling pathway. Differentially expressed genes of known or inferred function were assigned to the TGF- $\beta$ signalling pathway (based on the $H$. sapiens reference pathway hsa04350) by direct searching this pathway and by a literature search. Grey boxes: genes of the original pathway; white boxes/solid line: genes directly assigned to the pathway; white boxes/dashed line: genes assigned by literature search; bold style: upregulated at oestrus; italics: upregulated at dioestrus; for gene symbols in grey boxes see Entrez Gene www.ncbi.nlm.nih.gov/entrez/query.fcgi].

ECM remodelling indicates changes in the composition of the connective tissue during the oestrous cycle as proposed by Curry \& Osteen (2001). Furthermore, upregulation of mRNAs coding for proteins that negatively regulate cell growth and proliferation, and with apoptosis-related functions prevailed at oestrus. For proliferation-related/inhibiting genes these changes may reflect the end of the 'proliferative phase' of the endometrium since the animals representing day 0 were slaughtered at late oestrus.

At dioestrus, a number of transcripts for different enzymes and for proteins involved in transport processes are upregulated. The cyclic regulation of uterine fluids in the endometrium by differential expression of genes coding for ion channels was first shown by Chan et al.
(2002). The identification of three mRNAs coding for ion channels (group 'transport') provides further evidence for this. The upregulation of many mRNAs for enzymes may be to some extent an indication for the increase of the prostaglandin metabolism at dioestrus (Goff 2004, Spencer et al. 2004).

The genes of known function were further analysed in the context of different pathways where they are involved. The most prominent pathway was the TGF- $\beta$ signalling with 17 genes upregulated either at oestrus or at dioestrus. At oestrus, transcripts of target genes of this signalling pathway and transcripts for proteins that are shown to inhibit TGF- $\beta$ signalling were upregulated. In contrast, at dioestrus only three genes were identified which are described as being involved in TGF- $\beta$ 
产

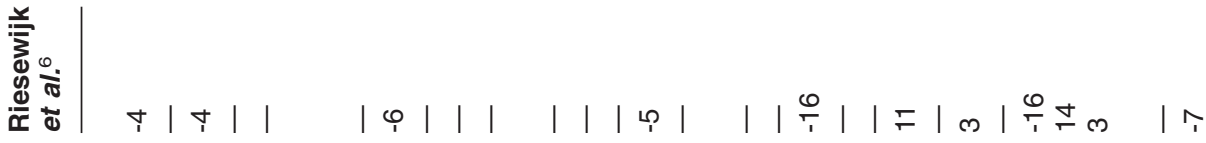

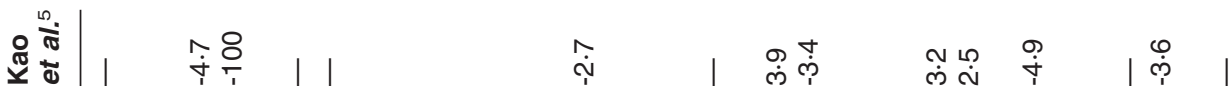

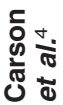

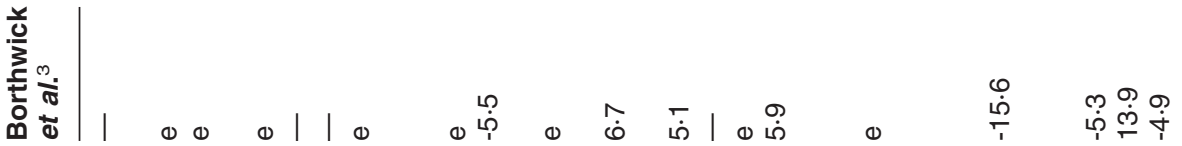

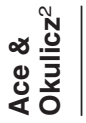



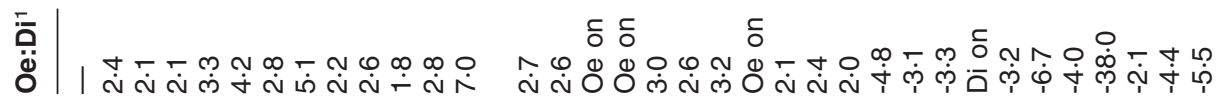




signalling. The identification of this considerable number of genes involved in or regulated by TGF- $\beta$ signalling is in line with current knowledge of regulation of the endometrium by TGF- $\beta$ during the oestrous cycle, implantation and pregnancy (Godkin \& Dore 1998, Tabibzadeh 2002). Furthermore, the induction of TGF- $\beta$ mRNAs and proteins by oestrogen has been shown in epithelial cells of the mouse endometrium (Nelson et al. 1992). This fits very well with the results of our study, where at late oestrus (oestrogen levels low) target genes of TGF- $\beta$ are still upregulated but negative regulators of this pathway are already present. Another pathway that could play a role in the regulation of the endometrial differentiation state is the RA signalling. In humans the regulatory role for endometrial maturation of RA signalling together with $\mathrm{P}_{4}$ and TGF- $\beta$ has already been described (Osteen et al. 2003). At dioestrus two mRNAs (CYP26A1, RDHE2) are elevated for proteins involved in RA metabolism whereas at oestrus the expression of two genes, which are described in context with differentiation was higher. Furthermore, the upregulation of mRNAs coding for proteins participating in the prostaglandin metabolism is consistent with the literature (Goff 2004, Spencer et al. 2004).

The comparison of the identified genes with microarray studies in other species revealed an overlap of $29 \%$, whereas half of the changes in mRNA concentrations for these genes were not in the same direction. For the interpretation of this result it has to be considered that the overlap between the human studies was also relatively small for different reasons (see Riesewijk et al. 2003) although the same microarray platform (Affymetrix) was used. Furthermore, there are substantial differences between species regarding (i) endometrial changes during the cycle (oestrous cycle lesser changes than during menstrual cycle) and (ii) the type of implantation of the embryo. In humans there is an early (at the blastocyst stage) and invasive implantation, whereas in the bovine species implantation is less invasive and follows an extended periimplantation period (after day 18 of the cycle) when the trophoblast spans nearly the complete uterus. In this context the comparison of these different gene expression profiles shows that there are common regulations but also distinct differences between species.

This is further supported by the expression patterns and/or potential functions that were already described for a number of the identified genes. Most of the data in the literature, although mainly derived from studies in other species, were in line with the results of the present study. Cycle-dependent expression with a higher level in proliferative in comparison with secretory phase endometrium was shown for example for CTSK (cathepsin K) (Jokimaa et al. 2001), PRSS11 (serine protease 11, insulin-like growth factor (IGF) binding) (De
Luca et al. 2003), PTHLH (parathyroid hormone-like hormone) (Hoshi et al. 2001), GJA1 (connexin 43) (Jahn et al. 1995), and $T \mathcal{N} C$ (tenascin C) mRNAs (Taguchi et al. 1999) in humans, and SPARC (osteonectin), COL5A2, COL6A3, LGALS1 (galectin 1) and SOX4 mRNAs in the Rhesus monkey (Ace \& Okulicz 2004). In sheep, GRP (gastrin-releasing peptide) mRNA (Whitley et al. 1998) and IGFBP6 (IGF-binding protein-6) mRNA (Gadd et al. 2002) showed maximal concentrations in the endometrium around ovulation. In the present study of bovine endometrium all these genes revealed higher expression levels at oestrus than at dioestrus. For two of these genes induction of mRNA expression by oestrogen has been shown in the endometrium of the rat for $G \mathcal{F} A 1$ (Grummer et al. 1994) and in human endometrial stromal cells for PTHLH (Casey et al. 1993). UTMP mRNA expression in sheep endometrium was detected at day 15 of the oestrous cycle (Stewart et al. 2000) but at oestrus UTMP expression was not analysed. Here we show highest expression of UTMP mRNA in the bovine endometrium of the cranial uterine horns at oestrus.

Increased endometrial mRNA levels during the secretory phase were described for the RA catabolic enzyme CIP26A1 (RA 4-hydroxylase), for TGM2 (tissue transglutaminase) (Deng et al. 2003), and for HPGD (15-hydroxyprostaglandin dehydrogenase) (Kelly et al. 1994) in humans and the PENK mRNA in the rat (Jin et al. 1988). In mouse endometrium, positive regulation of PENK by $\mathrm{P}_{4}$ has been indicated by a study of Cheon et al. (2002). In contrast to these findings, PENK is upregulated during proliferative phase in the endometrium of primates including humans (Low et al. 1989, Carson et al. 2002, Riesewijk et al. 2003, Ace \& Okulicz 2004). HPGD and TGM2 were also described to be upregulated by $\mathrm{P}_{4}$ (Fujimoto et al. 1996, Greenland et al. 2000). In sheep, TIMP2 (tissue inhibitor of metalloproteinase 2) mRNA (1.0 kb transcript) abundance in the endometrium has been shown to be stimulated by $\mathrm{P}_{4}$ and to be increased at day 10 of the cycle (Hampton et al. 1995). All these genes showed higher expression levels at dioestrus compared with oestrus in the bovine endometrium.

Furthermore, a role during pregnancy or the implantation process was shown or assumed for $A P O E$ (apolipoprotein E) (Overbergh et al. 1995), CLDN10 (claudin 10) (Wang et al. 2004), EFNA1 (ephrin A1) (Fujiwara et al. 2002), FBLN1 (fibulin 1) (Haendler et al. 2004), fibronectin (Rider et al. 1992), GJA1 (Gabriel et al. 2004), LGALS1 (Maquoi et al. 1997), MGP (matrix gla protein) (Spencer et al. 1999), MMP2 (matrix metalloproteinase 2) (Goffin et al. 2003), PENK (Jin et al. 1988), PLA2 G10 (phospholipase A2) (Goff 2004), SERPINA1 (Marshall \& Braye 1987), TNC (Michie \& Head 1994) and UTMP (Hansen 1998).

The endometrium is a relatively complex tissue composed of many different cell types. For the 
interpretation of differential gene expression the assignment to distinct cell types is important. Therefore, in situ hybridisations for five selected genes were done. All five genes were expressed specifically in the endometrium, mainly in the surface and the glandular epithelium. Nevertheless, there were distinct differences in their expression patterns, for example INHBA and PTHLH mRNAs were also detectable in fibroblasts of the stroma. The expression pattern of the UTMP mRNA in the bovine uterus at oestrus was similar to that found in sheep at day 19 of pregnancy (Stewart et al. 2000). For PENK the mRNA expression was highest in the deep glandular similar to the localisation in the mouse uterus (Rosen et al. 1990).

Our study is the first holistic screen for transcriptome changes in bovine endomtrium between oestrus and dioestrus. We identified a number of molecular pathways, most prominently the TGF- $\beta$ pathway, involved in the marked functional changes of endometrium between these two stages. To complete the analysis of gene expression during the oestrus cycle further stages (e.g. preoestrus and metoestrus) will be investigated and the function of candidate genes, e.g. UTMP, will be characterised. Furthermore, the differentially regulated genes identified in this study represent an important basis for future studies, e.g. on embryomaternal interactions during the pre-implantation period, and for differential diagnosis of fertility problems via array-based analysis of endometrial biopsies.

\section{Acknowledgements}

We thank Susanne Rehfeld, Peter Rieblinger, Christian Erdle and Myriam Weppert for excellent animal and sample management. This study was supported by the German Research Foundation (FOR 478/1). The authors declare that there is no conflict of interest that would prejudice the impartiality of this scientific work.

\section{References}

Ace CI \& Okulicz WC 2004 Microarray profiling of progesterone-regulated endometrial genes during the rhesus monkey secretory phase. Reproductive Biology and Endocrinology 254.

Bauersachs S, Blum H, Mallok S, Wenigerkind H, Rief S, Prelle K \& Wolf E 2003 Regulation of ipsilateral and contralateral bovine oviduct epithelial cell function in the postovulation period: a transcriptomics approach. Biology of Reproduction 68 1170-1177.

Bauersachs S, Rehfeld S, Ulbrich SE, Mallok S, Prelle K, Wenigerkind H, Einspanier R, Blum H \& Wolf E 2004 Monitoring gene expression changes in bovine oviduct epithelial cells during the oestrous cycle. Fournal of Molecular Endocrinology 32 449-466.

Borthwick JM, Charnock-Jones DS, Tom BD, Hull ML, Teirney R, Phillips SC \& Smith SK 2003 Determination of the transcript profile of human endometrium. Molecular Human Reproduction 9 19-33.
Carson DD, Lagow E, Thathiah A, Al Shami R, Farach-Carson MC, Vernon M, Yuan L, Fritz MA \& Lessey B 2002 Changes in gene expression during the early to mid-luteal (receptive phase) transition in human endometrium detected by high-density microarray screening. Molecular Human Reproduction 8 871-879.

Casey ML, Mibe M \& MacDonald PC 1993 Regulation of parathyroid hormone-related protein gene expression in human endometrial stromal cells in culture. Fournal of Clinical Endocrinology and Metabolism 77 188-194.

Chan LN, Tsang LL, Rowlands DK, Rochelle LG, Boucher RC, Liu CQ \& Chan HC 2002 Distribution and regulation of ENaC subunit and CFTR mRNA expression in murine female reproductive tract. Fournal of Membrane Biology 185 165-176.

Cheon YP, Li Q, Xu X, DeMayo FJ, Bagchi IC \& Bagchi MK 2002 A genomic approach to identify novel progesterone receptor regulated pathways in the uterus during implantation. Molecular Endocrinology 16 2853-2871.

Curry TE Jr \& Osteen KG 2001 Cyclic changes in the matrix metalloproteinase system in the ovary and uterus. Biology of Reproduction 64 1285-1296.

De Luca A, De Falco M, Severino A, Campioni M, Santini D, Baldi F, Paggi MG \& Baldi A 2003 Distribution of the serine protease HtrAl in normal human tissues. Fournal of Histochemistry and Cytochemistry 51 1279-1284.

Deng L, Shipley GL, Loose-Mitchell DS, Stancel GM, Broaddus R, Pickar JH \& Davies PJ 2003 Coordinate regulation of the production and signaling of retinoic acid by estrogen in the human endometrium. Fournal of Clinical Endocrinology and Metabolism 88 2157-2163.

Diatchenko L, Lau YF, Campbell AP, Chenchik A, Moqadam F, Huang B, Lukyanov S, Lukyanov K, Gurskaya N, Sverdlov ED et al. 1996 Suppression subtractive hybridization: a method for generating differentially regulated or tissue-specific cDNA probes and libraries. PNAS 93 6025-6030.

Fujimoto M, Kanzaki H, Nakayama H, Higuchi T, Hatayama H, Iwai M, Kaneko Y, Mori T \& Fujita J 1996 Requirement for transglutaminase in progesterone-induced decidualization of human endometrial stromal cells. Endocrinology 137 1096-1101.

Fujiwara H, Yoshioka S, Tatsumi K, Kosaka K, Satoh Y, Nishioka Y, Egawa M, Higuchi T \& Fujii S 2002 Human endometrial epithelial cells express ephrin A1: possible interaction between human blastocysts and endometrium via Eph-ephrin system. Fournal of Clinical Endocrinology and Metabolism 87 5801-5807.

Gabriel S, Winterhager E, Pfarrer C, Traub O \& Leiser R 2004 Modulation of connexin expression in sheep endometrium in response to pregnancy. Placenta 25 287-296.

Gadd TS, Osgerby JC \& Wathes DC 2002 Regulation of insulin-like growth factor binding protein-6 expression in the reproductive tract throughout the estrous cycle and during the development of the placenta in the ewe. Biology of Reproduction 67 1756-1762.

Godkin JD \& Dore JJ 1998 Transforming growth factor beta and the endometrium. Reviews of Reproduction 3 1-6.

Goff AK 2004 Steroid hormone modulation of prostaglandin secretion in the ruminant endometrium during the estrous cycle. Biology of Reproduction 71 11-16.

Goffin F, Munaut C, Frankenne F, Perrier DS, Beliard A, Fridman V, Nervo P, Colige A \& Foidart JM 2003 Expression pattern of metalloproteinases and tissue inhibitors of matrix-metalloproteinases in cycling human endometrium. Biology of Reproduction 69 976-984.

Greenland KJ, Jantke I, Jenatschke S, Bracken KE, Vinson C \& Gellersen B 2000 The human NAD+-dependent

15-hydroxyprostaglandin dehydrogenase gene promoter is controlled by Ets and activating protein-1 transcription factors and progesterone. Endocrinology 141 581-597.

Grummer R, Chwalisz K, Mulholland J, Traub O \& Winterhager E 1994 Regulation of connexin26 and connexin43 expression in rat 
endometrium by ovarian steroid hormones. Biology of Reproduction 51 1109-1116.

Haendler B, Yamanouchi H, Lessey BA, Chwalisz K \& Hess-Stumpp H 2004 Cycle-dependent endometrial expression and hormonal regulation of the fibulin-1 gene. Molecular Reproduction and Development 68 279-287.

Hampton AL, Butt AR, Riley SC \& Salamonsen LA 1995 Tissue inhibitors of metalloproteinases in endometrium of ovariectomized steroid-treated ewes and during the estrous cycle and early pregnancy. Biology of Reproduction 53 302-311.

Hansen PJ 1998 Regulation of uterine immune function by progesterone - lessons from the sheep. Fournal of Reproductive Immunology 40 63-79.

Hoshi S, Morimoto T, Saito H, Ichizuka K, Matsuoka R, Yanaihara A, Suzuki M, Yanaihara T \& Okai T 2001 PTHrP and $\mathrm{PTH} / \mathrm{PTHrP}$ receptor expressions in human endometrium. Endocrine Fournal 48 219-225.

Jahn E, Classen-Linke I, Kusche M, Beier HM, Traub O, Grummer R \& Winterhager E 1995 Expression of gap junction connexins in the human endometrium throughout the menstrual cycle. Human Reproduction 10 2666-2670.

Jin DF, Muffly KE, Okulicz WC \& Kilpatrick DL 1988 Estrous cycle- and pregnancy-related differences in expression of the proenkephalin and proopiomelanocortin genes in the ovary and uterus. Endocrinology 122 1466-1471.

Jokimaa V, Oksjoki S, Kujari H, Vuorio E \& Anttila L 2001 Expression patterns of cathepsins B, H, K, L and $\mathrm{S}$ in the human endometrium. Molecular Human Reproduction 7 73-78.

Kao LC, Tulac S, Lobo S, Imani B, Yang JP, Germeyer A, Osteen K, Taylor RN, Lessey BA \& Giudice LC 2002 Global gene profiling in human endometrium during the window of implantation. Endocrinology 143 2119-2138.

Kelly RW, Linan C, Thong J, Yong EL \& Baird DT 1994 Prostaglandin inactivation is increased in endometrium after exposure to clomiphene. Prostaglandins, Leukotrienes and Essential Fatty Acids $\mathbf{5 0} 235-238$.

Low KG, Nielsen CP, West NB, Douglass J, Brenner RM, Maslar IA \& Melner MH 1989 Proenkephalin gene expression in the primate uterus: regulation by estradiol in the endometrium. Molecular Endocrinology 3 852-857.

Malayer JR, Hansen PJ \& Buhi WC 1988 Effect of day of the oestrous cycle, side of the reproductive tract and heat shock on in vitro protein secretion by bovine endometrium. Fournal of Reproduction and Fertility 84 567-578.

Maquoi E, van den Brule FA, Castronovo V \& Foidart JM 1997 Changes in the distribution pattern of galectin- 1 and galectin-3 in human placenta correlates with the differentiation pathways of trophoblasts. Placenta 18 433-439.

Marshall RJ \& Braye SG 1987 Immunohistochemical demonstration of alpha-1-antitrypsin and alpha-1-antichymotrypsin in normal human endometrium. International Fournal of Gynecological Pathology 6 49-54.

Michie HJ \& Head JR 1994 Tenascin in pregnant and non-pregnant rat uterus: unique spatio-temporal expression during decidualization. Biology of Reproduction 50 1277-1286.

Nelson KG, Takahashi T, Lee DC, Luetteke NC, Bossert NL, Ross K, Eitzman BE \& McLachlan JA 1992 Transforming growth factor-alpha is a potential mediator of estrogen action in the mouse uterus. Endocrinology 131 1657-1664.

Neuvians TP, Pfaffl MW, Berisha B \& Schams D 2003 The mRNA expression of insulin receptor isoforms (IR-A and IR-B) and IGFR-2 in the bovine corpus luteum during the estrous cycle, pregnancy, and induced luteolysis. Endocrine 22 93-100.

Osteen KG, Igarashi TM \& Bruner-Tran KL 2003 Progesterone action in the human endometrium: induction of a unique tissue environment which limits matrix metalloproteinase (MMP) expression. Frontiers in Bioscience 8 d78-d86.

Overbergh L, Lorent K, Torrekens S, Van Leuven F \& Van den BH 1995 Expression of mouse alpha-macroglobulins, lipoprotein receptor-related protein, LDL receptor, apolipoprotein $\mathrm{E}$, and lipoprotein lipase in pregnancy. Fournal of Lipid Research $\mathbf{3 6}$ 1774-1786.

Pfaffl MW, Lange IG \& Meyer HH 2003 The gastrointestinal tract as target of steroid hormone action: quantification of steroid receptor mRNA expression (AR, ERalpha, ERbeta and PR) in 10 bovine gastrointestinal tract compartments by kinetic RT-PCR. Fournal of Steroid Biochemistry and Molecular Biology 84 159-166.

Prakash BS, Meyer HH, Schallenberger E \& van de Wiel DF 1987 Development of a sensitive enzyme immunoassay (EIA) for progesterone determination in unextracted bovine plasma using the second antibody technique. Fournal of Steroid Biochemistry 28 623-627.

Rider V, Carlone DL, Witrock D, Cai C \& Oliver N 1992 Uterine fibronectin mRNA content and localization are modulated during implantation. Developmental Dynamics 195 1-14.

Riesewijk A, Martin J, van Os R, Horcajadas JA, Polman J, Pellicer A, Mosselman S \& Simon C 2003 Gene expression profiling of human endometrial receptivity on days $\mathrm{LH}+2$ versus $\mathrm{LH}+7 \mathrm{by}$ microarray technology. Molecular Human Reproduction 9 253-264.

Rosen H, Itin A, Schiff R \& Keshet E 1990 Local regulation within the female reproductive system and upon embryonic implantation: identification of cells expressing proenkephalin A. Molecular Endocrinology 4 146-154.

Schams D \& Karg H 1969 [Radioimmunologic determination of LH in bovine serum, with special attention to the estrous cycle]. Acta Endocrinologica 61 96-103.

Spencer TE, Stagg AG, Joyce MM, Jenster G, Wood CG, Bazer FW, Wiley AA \& Bartol FF 1999 Discovery and characterization of endometrial epithelial messenger ribonucleic acids using the ovine uterine gland knockout model. Endocrinology 140 4070-4080.

Spencer TE, Johnson GA, Burghardt RC \& Bazer FW 2004 Progesterone and placental hormone actions on the uterus: insights from domestic animals. Biology of Reproduction 71 2-10.

Stewart MD, Johnson GA, Gray CA, Burghardt RC, Schuler LA, Joyce MM, Bazer FW \& Spencer TE 2000 Prolactin receptor and uterine milk protein expression in the ovine endometrium during the estrous cycle and pregnancy. Biology of Reproduction 62 1779-1789.

Tabibzadeh S 2002 Homeostasis of extracellular matrix by TGF-beta and lefty. Frontiers in Bioscience 7 d1231-d1246.

Taguchi M, Kubota T \& Aso T 1999 Immunohistochemical localization of tenascin and Ki-67 nuclear antigen in human endometrium throughout the normal menstrual cycle. Fournal of Medical and Dental Sciences 46 7-12.

Tan YF, Li FX, Piao YS, Sun XY \& Wang YL 2003 Global gene profiling analysis of mouse uterus during the oestrous cycle. Reproduction 126 171-182.

Ulbrich SE, Schoenfelder M, Thoene S \& Einspanier R 2004 Hyaluronan in the bovine oviduct-modulation of synthases and receptors during the estrous cycle. Molecular and Cellular Endocrinology 214 9-18.

Wang X, Matsumoto H, Zhao X, Das SK \& Paria BC 2004 Embryonic signals direct the formation of tight junctional permeability barrier in the decidualizing stroma during embryo implantation. Fournal of Cell Science 117 53-62.

Whitley JC, Shulkes A, Salamonsen LA, Vogiagis D, Familari M \& Giraud AS 1998 Temporal expression and cellular localization of a gastrin-releasing peptide-related gene in ovine uterus during the oestrous cycle and pregnancy. Fournal of Endocrinology 157 139-148.

Williams BL, Gwazdauskas FC \& Pearson RE 1992 The effect of day of the estrous cycle, location of ovulatory structure, and progesterone on in vitro bovine endometrial secretions. Fournal of Dairy Science 75 2112-2118.

Received 21 March 2005

Accepted 29 March 2005

Made available online as an Accepted Preprint 15 April 2005 